\title{
Improving replicability using interaction with laboratories: a multi-lab experimental assessment
}

\author{
Iman Jaljuli*1, Neri Kafkafi*1, ${ }^{2}$, Eliezer Giladi ${ }^{3}$, llan Golani ${ }^{2,4}$, Illana Gozes ${ }^{3}$, Elissa Chesler ${ }^{5}$, Molly A.
}

Bogue $^{5}$, Yoav Benjamini ${ }^{1,4}$

* These authors contributed equally to the paper.

Affiliations:

1. Department of Statistics and Operations Research, Tel-Aviv University, Tel-Aviv, Israel

2. School of Zoology, Faculty of Life Sciences, Tel Aviv University, Tel Aviv, Israel

3. The Elton Laboratory for Molecular Neuroendocrinology, Department of Human Molecular Genetics and Biochemistry, Sackler Faculty of Medicine, Sagol School of Neuroscience and Adams Super Center for Brain Studies, Tel Aviv University, Tel Aviv, Is rael.

4. The Sagol School of Neuroscience, Tel Aviv University, Tel Aviv, Israel

5. The Jackson Laboratory, Bar Harbor, ME, USA.

Keywords: reproducibility, genotype-by-lab interaction, treatment-by-genotype-by-lab interaction, preclinical morphology

\section{Abstract}

Phenotyping inbred and genetically-engineered mouse lines has become a central strategy for discovering mammalian gene function and evaluating pharmacological treatment. Yet the utility of any findings critically depends on their replicability in other laboratories. In previous publications we proposed a statistical approach for estimating the inter-laboratory replicability of novel discoveries in a single laboratory, and demonstrated that previous phenotyping results from multi-lab databases can be used to derive a Genotype-by-Lab (GxL) adjustment factor to ensure the replicability of single-lab results, for similarly measured phenotypes, even before making the effort of replicating the new finding in additional laboratories.

The demonstration above, however, still raised several important questions that could only be answered by an additional large-scale prospective experiment: Does GxL-adjustment works in single-lab experiments that were not intended to be standardized across laboratories? With genotypes that were not included in the previous experiments? And can it be used to adjust the results of pharmacological treatment experiments? We replicated results from five studies in the Mouse Phenome Database (MPD), in three behavioral tests, across three laboratories, offering 212 comparisons including 60 involving a pharmacological treatment: $18 \mathrm{mg} / \mathrm{kg} /$ day fluoxetine. In addition, we define and use a dimensionless $\mathrm{GxL}$ factor, derived from dividing the GxL variance by the standard deviation between animals within groups, as the more robust vehicle to transfer the adjustment from the multi-lab analysis to very different labs and genotypes.

For genotype comparisons, GxL-adjustment reduced the rate of non-replicable discoveries from $60 \%$ to $12 \%$, for the price of reducing the power to make replicable discoveries from $87 \%$ to $66 \%$. Another way to look at these results is noting that the adjustment could have prevented 23 failures to replicate, for the price of missing only three replicated ones. The tools and data needed for deployment of this method across other mouse experiments are publicly available in the Mouse Phenome Database.

Our results further point at some phenotypes as more prone to produce non-replicable results, while others, known to be more difficult to measure, are as likely to produce replicable results (once adjusted) as the physiological body weight is. 


\section{Introduction}

Phenotyping genetically engineered mouse lines has become a central strategy for discovering mammalian gene function (Gozes et al.,1993; Vulih-Shultzman et al., 2007; Hacohen-Kleiman et al., 2018; Karmon et al., 2021). While the mouse model may predict the human situation, the utility of any findings critically depends on their replicability in other laboratories (Kafkafi et al., 2018; Volkel et al., 2018). A similar doubt regarding the generalization of the effects afflicts single-lab preclinical testing of novel pharmacological treatments, requiring replicability in other models and in the clinical scenario (Javitt et al. 2012; Quraishe et al. 2013). In a previous publication (Kafkafi et al., 2017) we proposed a statistical approach for estimating the inter-laboratory replicability of novel discoveries in the level of the single laboratory study. This "Random Lab Model" (RLM, Kafkafi and Benjamini, 2005) approach adjusts any phenotyping discovery in a single laboratory, by adding the Genotype $x$ Laboratory $(\mathrm{GxL})$ interaction "noise" $\sigma_{G \times L}^{2}$ to the individual animal noise, thus generating a larger yardstick, against which genotype differences are tested. Consequently, "GxL adjustment" raises the benchmark for discovering a significant genotype effect, trading some statistical power for ensuring replicability. We demonstrated (Kafkafi et al., 2017) that previous phenotyping results from multi-lab databases can be used to derive a GxL-adjustment term to ensure the replicability of single-lab results, for the same phenotypes, even before making the effort of replicating the finding in additional laboratories.

The demonstration above, however, still raises several important questions: Kafkafi et al. (2017) used the GxL interaction in a multi-lab database to generate the GxL interaction factor, which was then used for adjusting the results of each of these labs separately, as if the results from the other labs were unknown. While the success of this demonstration is encouraging, it does not cover the realistic setting where the laboratories whose phenotyping results are being adjusted should be independent of the laboratories participating in the calculation of the GxL adjustment. For that purpose, we propose to use the GxL factor $\gamma \square=\square \sigma_{G \times L} \sigma$, where $\sigma$ is the pooled standard deviation within groups. The implication of this improvement is that rather than using the "raw" $\sigma_{G \times L}$ for adjustment, we multiply it by the ratio of the standard deviation in the adjusted study to the one in the multi-lab study from which the interaction is estimated. The use of the dimensionless factor $\gamma$ enables us to carry the information about the size of the interaction of a phenotype to other laboratories, other genotypes and variations in setups and conditions. We shall therefore first answer the question whether GxL adjustment reduces the proportion of nonreplicable results from that of the naïve analysis, and what loss of power does it involve.

A different yet important question is whether GxL estimation from standardized studies can be used to successfully identify replicable results in studies lacking special attention to standardization. Namely, will the adjustment based on the data from the International Mouse Phenome Consortium (IMPC, de Angelis et al., 2015; Muñoz-Fuentes et al., 2018), which typically uses relatively well-coordinated, standardized protocols, predict the replicability of results obtained in more common and realistic scenarios, such as those in the Mouse Phenome Database (MPD, Bogue et al., 2020). The MPD archives previous studies, that were not apriori meant to be part of a multi-lab project. Their methods, apparatus, endpoints and protocols of such experiments are thus not expected to be standardized.

Finally, our demonstration above tested genotype effects, using inbred strains and knockouts, but not pharmacological effects. It therefore remains to be tested whether the pre-estimated interaction of the genotype and pharmacological treatment with the lab (GXTxL) can also be used to adjust single-lab treatment testing in a similar way. 
In the present study we address these issues, by replicating experimental results previously submitted to the MPD across three laboratories (3-lab study), comparing the effects of genotypes and one pharmacological treatment (fluoxetine) in several behavioral phenotypes, as well as in one straightforward physiological phenotype (body weight). By conducting a 3-lab experiment without strong interlaboratories standardization and coordination, we intended to test the replicability of the original result, and assess to what extent the proposed GxL-adjustments used on the original results could predict its replicability. 


\section{Methods}

\subsection{Databases and replicated studies}

Two phenotypic databases are employed in this study: the Mouse Phenome Database (MPD, Bogue et al. 2020) and the International Mouse Phenotyping Consortium (IMPC, Muñoz-Fuentes et al., 2018). The MPD includes previous single-lab mouse studies submitted by data contributors, and here we attempt to replicate across three laboratories some of the results in these experiments. The IMPC data was used to estimate interaction terms across several IMPC centers, as in our previous study (Kafkafi et al. 2017). This is now implemented in the MPD: https://phenome.jax.org/replicability.

Results from five independent studies in the MPD including four tests were chosen to be replicated (MPD study code names as they appear on the MPD website): Wiltshire2 (Benton et al., 2012): Open-Field (OF), Tail-Suspension (TS); Tarantino2 (Schoenrock et al., 2016): OF; Crabbe4 (Crabbe et al., 2003): Grip Strength (GS); Tordoff3 (Tordoff et al. 2007): Body Weight (BW); Crowley1 (Crowley et al. 2010): BW.

Several considerations led us to select these studies: while searching the MPD for studies comparing many genotypes on many phenotypes, we nevertheless had to limit the number of animals being tested in our 3-lab experiment, by testing each mouse for several phenotypic endpoints. We therefore looked for studies in the MPD which: (i) shared the same genotypes and sexes; (ii) shared the same phenotypes; (iii) the phenotypes were also limited to those for which data from IMPC was available for the interaction terms; (iv) maximize the number of statistically significant findings in the MPD studies, since these are the only ones that might potentially be refuted by the GxL-adjustment. Still, whenever selecting several phenotypes and genotypes, many differences were not statistically significant in the original studies.

\subsection{Laboratories}

The three labs replicating the MPD studies were: The Center for Biometric Analysis (CBA) core facility The Jackson Laboratory, USA (JAX) under Bogue's supervision; The Laboratory in The George S. Wise Faculty of Life Sciences, Tel Aviv University, Israel (TAUL), under Gozes' supervision; The laboratory in the Faculty of Medicine, Tel Aviv University, Israel (TAUM) under Golani's supervision. At JAX mice were housed in the CBA animal room and testing was conducted in CBA procedure rooms; In TAUL, mice were housed in the Faculty of Life Animal House, and test were conducted by NK in the behavioral room in this facility. In TAUM, the animals were housed in David Glasberg Tower for Medical Research and tests were conducted by Eliezer Giladi (EG) on the $6^{\text {th }}$ floor of the Tower at the Myers Neuro-Behavioral Core Facility.

Note that the two labs in Tel Aviv University were in separate faculties and buildings, had separate experimental animals, facilities and technicians, and worked in independent time schedules. We took special care not to coordinate these two laboratories, as if each of them conducted the experiment in an independent study. Veterinary and Animal Care inspections in these two laboratories are both conducted by the TAU Center for Veterinary Care, but no active interference was required. All animal procedures in TAU were approved by TAU Institutional Animal Care and Use Committee and the Israeli Ministry of Health. At JAX, testing was performed in accordance with protocols approved by The Jackson Laboratory Institutional Animal Care and Use Committee. 


\subsection{Animals and Drugs}

All three labs used the inbred strains: BALB/cJ, BTBR $T^{+} \mid t p r 3^{\text {tf }} / J$ (BTBR), C57BL/6J, DBA/2J, SWR/J. The strain CBA/J was also used at TAUM and TAUL, but not at JAX. Breeders were transported from The Jackson Laboratory to each TAUM and TAUL, and were distributed to cages of one male and 2-3 females. 1 to 4 litters from each breeder cage were then separated at ages of approximately 50 to 60 days old, to cages of 2-5 mice of the same strain and sex. For the JAX experiment, mice were shipped from The Jackson Laboratory's production facility directly to JAX CBA and mice were identified by ear punch. In TAUL, mice were transferred to smaller cages in a different room than the breeders, and were identified by tail marks. Half of the male mice were administered $18 \mathrm{mg} / \mathrm{kg} /$ day fluoxetine in the drinking water (see below). Males were treated with fluoxetine, while females were not, because there was no MPD experiment in females that we could attempt to replicate. Mice were tested at similar ages (see below).

Fluoxetine $\mathrm{HCl}$ was purchased from Medisca Inc., Lot 172601 (Plattsburgh NY USA) for the JAX experiment. In TAU, commercial Fluoxetine $\mathrm{HCl}$ in $20 \mathrm{mg}$ capsules was purchased from Ely Lilly, Israel. As in Wiltshire2 (Benton et al., 2012), the average weight measurements for each strain, together with previously determined daily water intake for each strain, were used to determine the amount of fluoxetine required to provide a daily oral dose of 0 or $18 \mathrm{mg} / \mathrm{kg} / \mathrm{day}$ per mouse in drinking water. Male mice were treated daily with fluoxetine or water throughout the experiment. Fluoxetine treatment started at 5-6 weeks of age, in order to ensure three weeks of treatment before testing. In TAUM, the content of the water bottles changed every three days, while in TAUL and JAX they were changed every week, due to the use of larger bottles.

\subsection{Tests, phenotypes and testing parameters}

This study follows approximately the IMPC behavioral tests and protocols of Open filed (OF), Grip Strength (GS) and body weight (BW), from the behavioral pipeline of the IMPC IMPReSS EUMODIC pipeline 2 https://www.mousephenotype.org/impress/Pipelinelnfo?id=2 (Ayadi et al., 2012). In addition we replicated the Tail Suspension Test in Wiltshire2 (Benton et al., 2012), which is not included in the IMPC pipelines (see statistical methods).

The interaction terms with the laboratory were previously estimated across multiple laboratories by Kafkafi et al. 2017, and were also measured in experiments submitted to the MPD (see "Databases" above). Experiments and genotypes were chosen to maximize the number of tests and phenotypes with previous interaction terms from multiple labs, as explained in the considerations below. The OF test included the phenotypes (Table 1) of Distance Traveled (DT) and the percentage of time spent in the center (CT). The TS test measured the percentage of time spent in immobility, and the GS test measured forepaws peak grip strength, using the average of three consecutive measures.

Due to the differences between the IMPC pipeline and the different MPD studies, as well local constraints in the three labs, it was not feasible to precisely standardize the identity of tests, their order and the ages in which they were conducted. Indeed, such precise standardization does not represent the realistic situation of the field, and is unsuitable to the objective of this study. However, age differences in the timing of the each test were at most 5 weeks, and all mice were post-pubertal and relatively young adult ages, i.e., not middle aged ( 12 month) or aged ( $\approx 18+$ months). Table 1 summarizes the timelines in the databases, replicated MPD studies and the three labs. For similar reasons, the parameters and conditions of each test were not precisely standardized. These differences are detailed below, and for the OF test are also summarized in Table 2. 
In the OF test, the phenotypes of distance traveled and percent of time spent in the center, in a small arena, for 10 and 20 minutes were recorded. In TAUL and TAUM these were also measured in a large arena (Table 2).

Open Field (OF) methods: Mice were allowed to acclimate to the testing room for a minimum of $60 \mathrm{~min}$. Arena parameters were slightly different in some of the IMPC database, MPD studies and the three replicated labs, and are summarized in Table 2 . The apparatus was a square chamber, either $27 \times 27 \mathrm{~cm}$ ("small") for males (as in Wiltshire2) or $40 \times 40 \mathrm{~cm}$ to $50 \times 50 \mathrm{~cm}$ ("large") for females (as in Tarantino 2 and the IMPC protocol). In TAUL and TAUM, the males were also tested in a large arena, a week after all the other tests were concluded (Table 2), in order to facilitate comparisons with the IMPC results.

Center and periphery definitions were also different (Table 2). The Session duration was 20 min (as in the IMPC protocol), but with all analysis was done for the first 10 minutes (as in Wiltshire2) as well. In each test, the total Distance Traveled (DT) and the percentage of session time spent in the center of the arena (CT) were measured. In addition, TAUL and TAUM also tested the control and fluoxetine males in a second OF session in the "large" arenas (as in the IMPC database) about a week after completing all other tests. Between subjects, the arena was cleaned with $70 \%$ ethanol. In TAUL, mice were tested four at a time in four square Plexiglas arenas. To begin each test, the mouse was placed in the center of the arena. The apparatus was a square chamber either $27 \times 27 \mathrm{~cm}$ or $50 \times 50 \mathrm{~cm}$. Tracking and Analysis was conducted using a Noldus EthoVision video tracking system. In TAUM, mice were tested 4 at a time in 4 square Plexiglas cages. To begin each test, the mouse was placed in the center of the arena. The apparatus was a square chamber either $27 \times 27 \mathrm{~cm}$ or $50 \times 50 \mathrm{~cm}$. Video Tracking and Analysis was done with Noldus EthoVision video tracking system. In JAX, mice were acclimated to the testing room for a minimum of 60 min. The apparatus (Omnitech Electronics, Inc., Columbus OH, USA) was a square chamber (40 $\times 40$ $\mathrm{cm})$. To begin each test, the mouse was placed in the center of the arena. Data were recorded via sensitive infrared photobeams, and collected in 5-min bins. 
bioRxiv preprint doi: https://doi.org/10.1101/2021.12.05.471264; this version posted December 7, 2021. The copyright holder for this preprint (which was not certified by peer review) is the author/funder, who has granted bioRxiv a license to display the preprint in perpetuity. It is made available under aCC-BY-NC-ND 4.0 International license.

Table 1: Timelines of animals and tests participating in the IMPC database (EUMODIC Pipeline 2), in the 5 replicated studies in the MPD database, and in the three labs participating in the experiment: TAUL, TAUM and JAX. Tests in Bold letters are common to all databases and labs.

\begin{tabular}{|c|c|c|c|c|c|c|c|c|c|}
\hline $\begin{array}{l}\text { Week } \\
\text { after } \\
\text { birth }\end{array}$ & $\begin{array}{l}\text { IMPC (EUMODIC } \\
\text { Pipeline 2) } \\
\text { [ESLIM_002] }\end{array}$ & $\begin{array}{l}\text { MPD: } \\
\text { Crabbe4 }\end{array}$ & $\begin{array}{l}\text { MPD: } \\
\text { Tarantino2 }\end{array}$ & $\begin{array}{l}\text { MPD: } \\
\text { Tordoff3 }\end{array}$ & $\begin{array}{l}\text { MPD: } \\
\text { Wiltshire2 }\end{array}$ & $\begin{array}{l}\text { MPD: } \\
\text { Crowley1 }\end{array}$ & TAUL & TAUM & JAX \\
\hline 5 & & Shipping & Shipping & & Shipping & & Moving & & Shipping \\
\hline 6 & & Shipping & Shipping & & $\begin{array}{l}\text { Begin } \\
\text { fluoxetine }\end{array}$ & & $\begin{array}{l}\text { Begin } \\
\text { fluoxetine }\end{array}$ & $\begin{array}{l}\text { Begin } \\
\text { fluoxetine }\end{array}$ & $\begin{array}{l}\text { Begin } \\
\text { fluoxetine }\end{array}$ \\
\hline 7 & & GS & $\begin{array}{l}\text { Sham } \\
\text { surgery }\end{array}$ & & & & & & \\
\hline 8 & & GS & & BW & & Shipping & GS; BW & GS; BW & GS; BW \\
\hline 9 & $\begin{array}{l}\text { OF large arena } \\
\text { GS; BW; } \\
\text { Modified SHIRPA }\end{array}$ & GS & & $\begin{array}{l}\text { BW; } \\
\text { preference } \\
\text { for } \mathrm{CaCl}_{2}\end{array}$ & TS & BW & $\begin{array}{l}\text { GS; BW } \\
\text { OF females: } \\
\text { large arena } \\
\text { OF males: } \\
\text { small arena }\end{array}$ & $\begin{array}{l}\text { GS; BW } \\
\text { OF } \\
\text { females: } \\
\text { large } \\
\text { arena } \\
\text { OF males: } \\
\text { small } \\
\text { arena }\end{array}$ & $\begin{array}{l}\text { GS; BW; } \\
\text { OF } \\
\text { females: } \\
\text { large } \\
\text { arena }\end{array}$ \\
\hline 10 & Rotarod & GS & $\begin{array}{l}\text { OF females: } \\
\text { Large arena }\end{array}$ & BW & $\begin{array}{l}\text { TS; OF } \\
\text { males, } \\
\text { small } \\
\text { arena }\end{array}$ & & $\begin{array}{l}\text { OF females: } \\
\text { large arena } \\
\text { OF males: } \\
\text { small arena }\end{array}$ & $\begin{array}{l}\text { OF } \\
\text { females: } \\
\text { large } \\
\text { arena } \\
\text { OF males: } \\
\text { small } \\
\text { arena }\end{array}$ & $\begin{array}{l}\text { OF } \\
\text { females: } \\
\text { large } \\
\text { arena }\end{array}$ \\
\hline 11 & $\begin{array}{l}\text { Acoustic startle } \\
\text { \& PPI }\end{array}$ & GS & $\begin{array}{l}\text { OF females: } \\
\text { Large arena }\end{array}$ & & $\begin{array}{l}\text { OF males, } \\
\text { small } \\
\text { arena }\end{array}$ & & $\begin{array}{l}\text { OF females: } \\
\text { large arena } \\
\text { OF males: } \\
\text { small arena } \\
\text { TS }\end{array}$ & $\begin{array}{l}\text { OF } \\
\text { females: } \\
\text { large } \\
\text { arena } \\
\text { OF males: } \\
\text { small } \\
\text { arena TS }\end{array}$ & $\begin{array}{l}\text { OF males: } \\
\text { large } \\
\text { arena; TS }\end{array}$ \\
\hline 12 & Hot Plate & GS & $\begin{array}{l}\text { OF females: } \\
\text { Large arena }\end{array}$ & & & & $\begin{array}{l}\mathbf{T S} ; \\
\text { OF males, } \\
\text { large arena }\end{array}$ & $\begin{array}{l}\text { TS; } \\
\text { OF males, } \\
\text { large } \\
\text { arena }\end{array}$ & $\begin{array}{l}\text { OF males: } \\
\text { large } \\
\text { arena; TS }\end{array}$ \\
\hline 13 & Blood tests & & & & & & $\begin{array}{l}\text { OF males, } \\
\text { large arena }\end{array}$ & $\begin{array}{l}\text { OF males, } \\
\text { large } \\
\text { arena }\end{array}$ & $\begin{array}{l}\text { OF males: } \\
\text { large } \\
\text { arena }\end{array}$ \\
\hline
\end{tabular}


bioRxiv preprint doi: https://doi.org/10.1101/2021.12.05.471264; this version posted December 7, 2021. The copyright holder for this preprint (which was not certified by peer review) is the author/funder, who has granted bioRxiv a license to display the preprint in perpetuity. It is made available under aCC-BY-NC-ND 4.0 International license.

Table 2: OF parameters used in different mouse groups in each of the three labs, in the IMPC database and in the MPD studies.

\begin{tabular}{|c|c|c|c|c|c|c|c|}
\hline Lab & Gender & Age & Treatment & $\begin{array}{l}\text { Arena } \\
\text { Size }\end{array}$ & $\begin{array}{l}\text { Tracking method } \\
\text { (system, company) }\end{array}$ & $\begin{array}{l}\text { Periphery } \\
\text { definition }\end{array}$ & $\begin{array}{l}\text { Session } \\
\text { duration }\end{array}$ \\
\hline TAUM & Females & 10 weeks & Control & $42 \mathrm{~cm}$ & $\begin{array}{l}\text { Video (Ethovision, } \\
\text { Noldus) }\end{array}$ & $10 \mathrm{~cm}$ & $\begin{array}{l}10,20 \\
\min \end{array}$ \\
\hline TAUL & Females & 9-11 weeks & Control & $42 \mathrm{~cm}$ & $\begin{array}{l}\text { Video (Ethovision, } \\
\text { Noldus) }\end{array}$ & $10 \mathrm{~cm}$ & $\begin{array}{l}10,20 \\
\min \end{array}$ \\
\hline JAX & Females & 9-11 weeks & Control & $40 \mathrm{~cm}$ & $\begin{array}{l}\text { Photobeam } \\
\text { (Omnitech) }\end{array}$ & $8 \mathrm{~cm}$ & $\begin{array}{l}10,20 \\
\min \end{array}$ \\
\hline IMPC & Females & 8 weeks & Control & $\begin{array}{l}40-44 \\
\mathrm{~cm}\end{array}$ & $\begin{array}{l}\text { Video (Ethovision, } \\
\text { Noldus) }\end{array}$ & $16 \mathrm{~cm}$ & $20 \mathrm{~min}$ \\
\hline Tarantino2 & Females & 11 weeks & Control & $42 \mathrm{~cm}$ & $\begin{array}{l}\text { Photocell (Versamax, } \\
\text { AccuScan, Columbus) }\end{array}$ & $9.57 \mathrm{~cm}$ & $10 \mathrm{~min}$ \\
\hline TAUM & males & 10 weeks & Control & $27 \mathrm{~cm}$ & $\begin{array}{l}\text { Video (Ethovision, } \\
\text { Noldus) }\end{array}$ & $8 \mathrm{~cm}$ & $\begin{array}{l}10,20 \\
\min \end{array}$ \\
\hline TAUL & males & 9-11 weeks & Control & $27 \mathrm{~cm}$ & $\begin{array}{l}\text { Video (Ethovision, } \\
\text { Noldus) }\end{array}$ & $8 \mathrm{~cm}$ & $\begin{array}{l}10,20 \\
\min \end{array}$ \\
\hline JAX & males & 9-11 weeks & Control & $40 \mathrm{~cm}$ & $\begin{array}{l}\text { Photobeam } \\
\text { (Omnitech) }\end{array}$ & $8 \mathrm{~cm}$ & $\begin{array}{l}10,20 \\
\min \end{array}$ \\
\hline IMPC & males & 8 weeks & Control & $\begin{array}{l}40-44 \\
\mathrm{~cm}\end{array}$ & $\begin{array}{l}\text { Video (Ethovision, } \\
\text { Noldus) }\end{array}$ & $16 \mathrm{~cm}$ & $20 \mathrm{~min}$ \\
\hline Wiltshire2 & males & $\begin{array}{l}10-11 \\
\text { weeks }\end{array}$ & Control & $\begin{array}{l}27.3 \\
\mathrm{~cm}\end{array}$ & $\begin{array}{l}\text { Photobeam (MED- } \\
\text { OFA-MS, Med } \\
\text { Associates) }\end{array}$ & $6.8 \mathrm{~cm}$ & $10 \mathrm{~min}$ \\
\hline TAUM & males & 9-11 weeks & Fluoxetine & $27 \mathrm{~cm}$ & $\begin{array}{l}\text { Video (Ethovision, } \\
\text { Noldus) }\end{array}$ & $8 \mathrm{~cm}$ & $\begin{array}{l}10,20 \\
\min \end{array}$ \\
\hline TAUL & males & 9-11 weeks & Fluoxetine & $27 \mathrm{~cm}$ & $\begin{array}{l}\text { Video (Ethovision, } \\
\text { Noldus) }\end{array}$ & $8 \mathrm{~cm}$ & $\begin{array}{l}10,20 \\
\min \end{array}$ \\
\hline JAX & males & 9-11 weeks & Fluoxetine & $40 \mathrm{~cm}$ & $\begin{array}{l}\text { Photobeam } \\
\text { (Omnitech) }\end{array}$ & $8 \mathrm{~cm}$ & $\begin{array}{l}10,20 \\
\min \end{array}$ \\
\hline TAUM & males & $\begin{array}{l}11-12 \\
\text { weeks }\end{array}$ & Control & $42 \mathrm{~cm}$ & Video (Noldus) & $10 \mathrm{~cm}$ & $\begin{array}{l}10,20 \\
\min \end{array}$ \\
\hline TAUL & males & $\begin{array}{l}11-12 \\
\text { weeks }\end{array}$ & Control & $42 \mathrm{~cm}$ & Video (Noldus) & $10 \mathrm{~cm}$ & $\begin{array}{l}10,20 \\
\min \end{array}$ \\
\hline TAUM & males & $\begin{array}{l}11-12 \\
\text { weeks }\end{array}$ & Fluoxetine & $42 \mathrm{~cm}$ & Video (Noldus) & $10 \mathrm{~cm}$ & $\begin{array}{l}10,20 \\
\min \end{array}$ \\
\hline
\end{tabular}

Grip Strength (GS) methods: Three trials were carried out in succession measuring forelimb-strength only, and the final result was their average, as in the replicated MPD experiment Crabbe4 (Crabbe et al. 2003) and the IMPC protocol. The mouse was held by the tail, lowered over the grid, keeping the torso horizontal and allowing only its forepaws to attach to the grid before any measurements were taken. The mouse was pulled gently back by its tail, ensuring the grip the on the top portion of the grid, with the 
torso remaining horizontal. The testing area was cleaned with $70 \%$ ethanol between subjects. In TAUL, TSE Systems Grip Strength Meter for mice was used with a mesh grid. In TAUM a commercially available Ugo Basile Grip-Strength Meter was used with a wire grid, coupled with a strain gauge measuring peak force in $\mathrm{kg}$. In JAX, mice were acclimated for 60 min prior to testing. A commercially available grip strength meter (Bioseb, Pinellas Park FL, USA) was used.

Tail Suspension (TS) methods: Mice were allowed to acclimate to the testing room for a minimum of 60 min prior to testing. They were suspended by their tails with adhesive tape to the top of Plexiglas cages. The percentage of time spent it immobility was measured in 6 and in 7 minutes. Between subjects, the testing area was cleaned with $70 \%$ ethanol. We used the 7 min data, as did Wiltshire2 (Benton et al., 2012) who reported dropping the first 1 minute because all mice remained mobile throughout. This led to not dropping the last minute in our results, and should hardly affect differences. In TAUL, Tracking and Analysis was measured with Noldus EthoVision video tracking system. Polyethylene cylinders about 24 $\mathrm{mm}$ tall and $10 \mathrm{~mm}$ in diameter on the base of the tail were used to minimize the ability of mice to climb on their tail. Several mice that did manage to climb on the tail were discarded from analysis, as in the original Wiltshire2 experiment (Benton et al., 2012). In TAUM, Tracking and Analysis was measured with Noldus EthoVision video tracking system. In JAX, standard Med-Associates (St. Albans VT, USA) Tail Suspension Test chambers were used. Mice (10-12 weeks) were suspended by their tails with adhesive tape (VWR or Fisher, $25 \mathrm{~mm}$ wide) to a flat metal bar connected to a force transducer that measures transduced movement. The tape was extended the length of the mouse's tail from $2 \mathrm{~mm}$ from base through $2 \mathrm{~mm}$ from tip, minimizing the ability of the mouse to climb its tail. A computer interfaced to the force transducer recorded the data.

Number of animals: We designed the experiment for at least $n=10$ mice per group. In some groups the number of animals was larger, due to litter sizes. In 10\% (52/505) of the groups there were 9 animals. However, in tail suspension testing in JAX, some mice climbed their tails and no measurements were available, resulting in 4 measurements per group in four groups of females; 6 measurements per group and 8 measurements per group in 4 and 3 groups of males respectively. In $6 \%$ of the groups there were 15 or more animals. In the MPD experiments the number of mice per group ranged from 5 to 20 , with median of 10.5 and interquartile range of 5 . In the IMPC data the number of mice per group ranged from 3 to 403 , with a median of 8 and interquartile range of 3 . We obviously had no control of the number of mice in the MPD and IMPC.

\subsection{Statistical Methods}

\subsubsection{GxL-adjustment of genotype effect in a single-lab study}

The conventional t-test for testing phenotypic difference between genotype $\mathrm{x}$ and genotype $\mathrm{y}$, is:

$$
\frac{\bar{x}-\bar{y}}{s_{p} \sqrt{\frac{1}{n_{1}}+\frac{1}{n_{2}}}}
$$

where $\mathrm{n}_{1}$ is group size for genotype $\mathrm{x}$ and $\mathrm{n}_{2}$ for genotype $\mathrm{y}$, and $s_{p}$ is the pooled standard deviation within the groups. The number of degrees of freedom is $d f=n_{1}+n_{2}-2$. The underlying assumptions are that both genotype groups are independent, that both have equal within group variances, and that the distribution of the phenotype is approximately Gaussian Appropriate transformations of the original measurements such as log, logit and power were used to make these assumptions more appropriate. The test can be modified if the variances are grossly unequal in the two groups. 
The random lab model (RLM) for replicability. When a phenotype is compared between $\mathrm{G}$ genotypes in L laboratories, Kafkafi et al (2017) introduced the existence of Genotype by Lab interaction (GxL), i.e., $\operatorname{Cov}(\bar{x}, \bar{y})=\sigma_{G \times L}^{2}$, and suggested to treat it as random. This alters the t-test as follows:

$$
\frac{\bar{x}-\bar{y}}{\sqrt{s_{p}^{2}\left(\frac{1}{n_{1}}+\frac{1}{n_{2}}\right)+2 \sigma_{G \times L}^{2}}}
$$

where $\sigma_{G \times L}^{2}$ is the variance introduced into the comparison of the means by the random interaction.

GxL-adjustment from a database. We define the GxL factor $\gamma$ estimated from the results of a multi-lab study or database, as the square root of the ratio of the interaction variance to the pooled within-group error in the variance:

$$
\gamma=\sqrt{\frac{\sigma_{G \times L}^{2}}{\sigma^{2}}}
$$

When using GxL-adjustment at the single lab, the t-test, with its estimated standard deviation $s_{p}$, becomes

$$
T=\frac{\bar{x}-\bar{y}}{s_{p} \sqrt{\left(\frac{1}{n_{1}}+\frac{1}{n_{2}}\right)+2 \gamma^{2}}} .
$$

Underlying such use is the assumption that $s_{p}{ }^{2} \gamma^{2}=\frac{s_{p}^{2}}{\sigma^{2}} \sigma_{G \times L}^{2}$ is approximately the relevant interaction term if this single lab study was part of such multi-lab analysis. Multiplying the database estimated interaction variance by the ratio of the variance in the adjusted single lab to the pooled variance in the multi-lab database translates the interaction term in one set of labs into a more relevant one in the single lab.

In a pre-clinical experiment involving laboratory mice and rats, a typical batch size is of 10-20 animals. Hence, $1 / n_{i}$ is typically smaller than 0.1 . This gives us an interpretation of the size of $\gamma^{2}: \gamma^{2} \approx 0.1$, namely $\gamma \approx 0.3$, is of the same order as $1 / n$, and $\gamma^{2}>1$ would have a very large effect. Note that the group sizes $n_{1}, n_{2}$ do not have any effect on the GxL factor $\gamma$. That is, if the interaction variance is large, increasing the number of animals can hardly improve replicability.

The distribution of T is approximated by $t$ with $v$ degrees of freedom using Satterthwaite formula: Let $n_{L}$ and $n_{s}$ denote the number of labs, and genotypes used for estimating $\gamma^{2}$

$$
v=\frac{s_{p}^{4}\left(\frac{1}{n_{1}}+\frac{1}{n_{2}}+2 \gamma^{2}\right)^{2}}{s_{p}^{4}\left(\frac{1}{n_{1}}+\frac{1}{n_{2}}\right)^{2} \frac{1}{n_{1}+n_{2}-2}+4 s_{p}^{4} \gamma^{4} \frac{1}{\left(n_{L}-1\right)\left(n_{S}-1\right)}} .
$$

\subsubsection{Using GxL-adjustment for treatment effect}

The database which we use for estimating the adjustment size $-\gamma^{2}$ - only offers it for tests where animals were not treated, although tests for treatment effect are an important part of animal testing. Note that the adjusted test statistic $\mathrm{T}$ is still valid in case where both groups are treated with similar treatment. 
Therefore, we also use it to test the replicability of strain effect when both groups are treated with Fluoxetine, even though the adjustment component was estimated via untreated animals.

Multi-lab experiment that also included treatment groups is analyzed using a random-lab 3-way analysis, where treatment effect is added as a fixed effect, in addition to the factors we originally have in the random-lab 2-way analysis. We also include interactions involving treatment of all orders, namely, treatment-by-genotype, treatment-by-lab, genotype-by-lab and treatment-by-genotype-by-lab where the proportional SD of the latter interaction to error SD is denoted by $\gamma_{T \times G \times L}$.

In their paper (Benton et al., 2012) Wiltshire2 test the effect of fluoxetine treatment for each genotype (see e.g., the figure in https://phenome.jax.org/measureset/38005 for the DS phenotype comparing treatment effects between the different strains. In such a case, a linear contrast could have been performed for statistically based inference as follows:

$$
\frac{\left(\bar{x}_{T}-\bar{x}_{C}\right)-\left(\bar{y}_{T}-\bar{y}_{C}\right)}{s_{p} \sqrt{\frac{1}{n_{1 T}}+\frac{1}{n_{1 C}}+\frac{1}{n_{2 T}}+\frac{1}{n_{2 C}}}}
$$

Where $\bar{x}_{T}, \bar{x}_{C}$ denote the mean size at the treatment and control groups of the first genotype, respectively, and $n_{1 T}, n_{1 C}$ denote their sample sizes. For the second genotype, $\bar{y}_{T}, \bar{y}_{C}$ denote the mean size at the treatment and control groups, respectively and $n_{2 T}, n_{2 C}$ denote their sample sizes.

The second order interaction of treatment by genotype is the fixed parameter we try to estimate. All other second order interactions, namely treatment-by-lab and the genotype-by-lab cancel out in the contrast. What remains is the third order interaction treatment-by-genotype-by-lab ( $T x G x L)$ that specifies the random contribution of the laboratory on the measurement for a specific genotype when treated and another one when not. Since there are 4 of these, and they are independent, they increase the variance by $4 s_{p}^{2} \gamma_{T \times G \times L}^{2}$,

$$
\frac{\left(\bar{x}_{T}-\bar{x}_{C}\right)-\left(\bar{y}_{T}-\bar{y}_{C}\right)}{s_{p} \sqrt{\left(\frac{1}{n_{1 T}}+\frac{1}{n_{1 C}}+\frac{1}{n_{2 T}}+\frac{1}{n_{2 C}}\right)+4 \gamma_{T \times G \times L}^{2}}}
$$

The degrees of freedom are recalculated again according to Satterthwaite formula. As previously mentioned, we do not have an outer (independent) source to estimate the size of this interaction. Therefore, we estimate it using the data collected by our 3-lab experiment, and we apply it on the t-tests of the original Wiltshire2 study. Due to the lack of a third-party estimate, we are unable to demonstrate the power and type-I error of the tool, but merely assess the robustness of the original study results to the proposed adjustment.

\subsubsection{Displaying the results}

To study the effect of the adjustment we treat our 3-lab replication results as our "ground truth", where a statistically-significant difference is considered a "replicated difference" (Table 3 first column). For each difference between two strains in each phenotype we then examine if (second column) this difference was significant in the original single-lab study in the MPD, and if (third column) it is still significant after correcting it using the GxL-adjustment previously calculated in the IMPC (Kafkafi et al., 2017). The six possible combinations are denoted by categories A-F (fourth column), with their interpretations (fifth 
column). In addition, we find the ratio out of the non-replicable differences (categories $D+E+F$ ) that were inappropriately discovered by the original analysis study $(D+E)$ and the same proportion after both adjustments (D). As to loss of replicable discoveries the proportion of replicated ones discovered by the original analysis and after its adjustment are given by the last two lines in the table. (Note that if we treat replicated difference as 'true' and non-replicated difference as false we discuss Type-I error and power with and without adjustment)

Table 3. The results tables in the "Results" section use the same structure, categories and interpretation.

\begin{tabular}{|l|l|l|l|l|}
\hline $\begin{array}{c}\text { “Ground truth" } \\
\text { by 3-Lab study }\end{array}$ & $\begin{array}{l}\text { Single-lab } \\
\text { difference }\end{array}$ & $\begin{array}{l}\text { Single-lab } \\
\text { GxL-adjusted }\end{array}$ & Category & Interpretation \\
\hline Replicable & significant & significant & A & Replicable discoveries, approved by adjustment \\
\hline Replicable & significant & ns & B & Replicable discoveries, missed by adjustment \\
\hline Replicable & ns & ns & C & Replicable discoveries missed by both \\
\hline Non-replicable & significant & significant & D & Non-replicable, insufficient adjustment \\
\hline Non-replicable & significant & ns & E & Non- replicable, prevented by adjustment \\
\hline Non-replicable & ns & ns & F & Non-replicable by both \\
\hline & & & $(D+E) /(D+E+F)$ & Proportion of non-replicable discoveries \\
\hline & & & $(D) /(D+E+F)$ & Proportion of non-replicable discoveries, GxL-adjusted \\
\hline & & & $(A+B) /(A+B+C)$ & Power to discover replicable discoveries \\
\hline & & & $(A) /(A+B+C)$ & Power to discover replicable discoveries, GxL-adjusted \\
\hline
\end{tabular}

\subsubsection{Computational details and data availability}

Statistical analysis was done in R version 4.1 .1 (2021-08-10) (R Core Team, 2021). We use the packages "Ime4" (Bates et al. 2015), "nlme" (Pinheiro et al. 2021) and "multcomp" (Hothorn et al. 2008) to perform multi-lab analysis via Restricted Maximum Likelihood (REML) and pairwise comparisons. Figures shown in this paper are produced with the package "ggplot2" (Wickham, 2016).

Raw data files and $R$ code for reproducible research is available online at GitHub URL: https://github.com/IJaljuli/Improving-replicability-using-interaction-2021. 


\section{Results}

\subsection{Replication in the 3-lab experiment}

We use our 3-lab experiment to evaluate whether the specific MPD studies' results are replicable or not, using the RLM analysis. Therefore, figs. 1 to 7 display the 3-lab results and their summaries, together with the standard deviation of the within-group error, and the standard deviation of the GXL interaction. Consider for example Fig. 1 displaying the BW phenotype results: Each boxplot (top) displays the results for one genotype (identified on the bottom of the figure) in one lab. The three boxplots summarizing the three lab results for each genotype are clustered together. When available for this genotype, a forth boxplot displays the corresponding result from the original MPD study, in this case Crowley1 for females or Tordoff3 for males. The three panels display results for the females (left), the control males (center) and the fluoxetine-treated male (right). The bottom part of the figure displays the averages of the values in the boxplots, in this case in the original scale, but in other figures in the transformed scale, when a transformation was used for the analysis. Note that there are some consistent differences between labs, expressed as vertical distances between lab lines, but these will not affect the replicability when comparing genotypes within the same lab. The concern is rather the GxL interaction, which can be perceived by differences in slope across lab lines, where parallel lines represent no interaction. The black error bars represent the interaction SD and the within-group error SD (as in Kafkafi et al. 2005; Kafkafi et al. 2017). The ratio of the first to the second bars is the estimated parameter $\gamma$ (see Statistical Methods). 


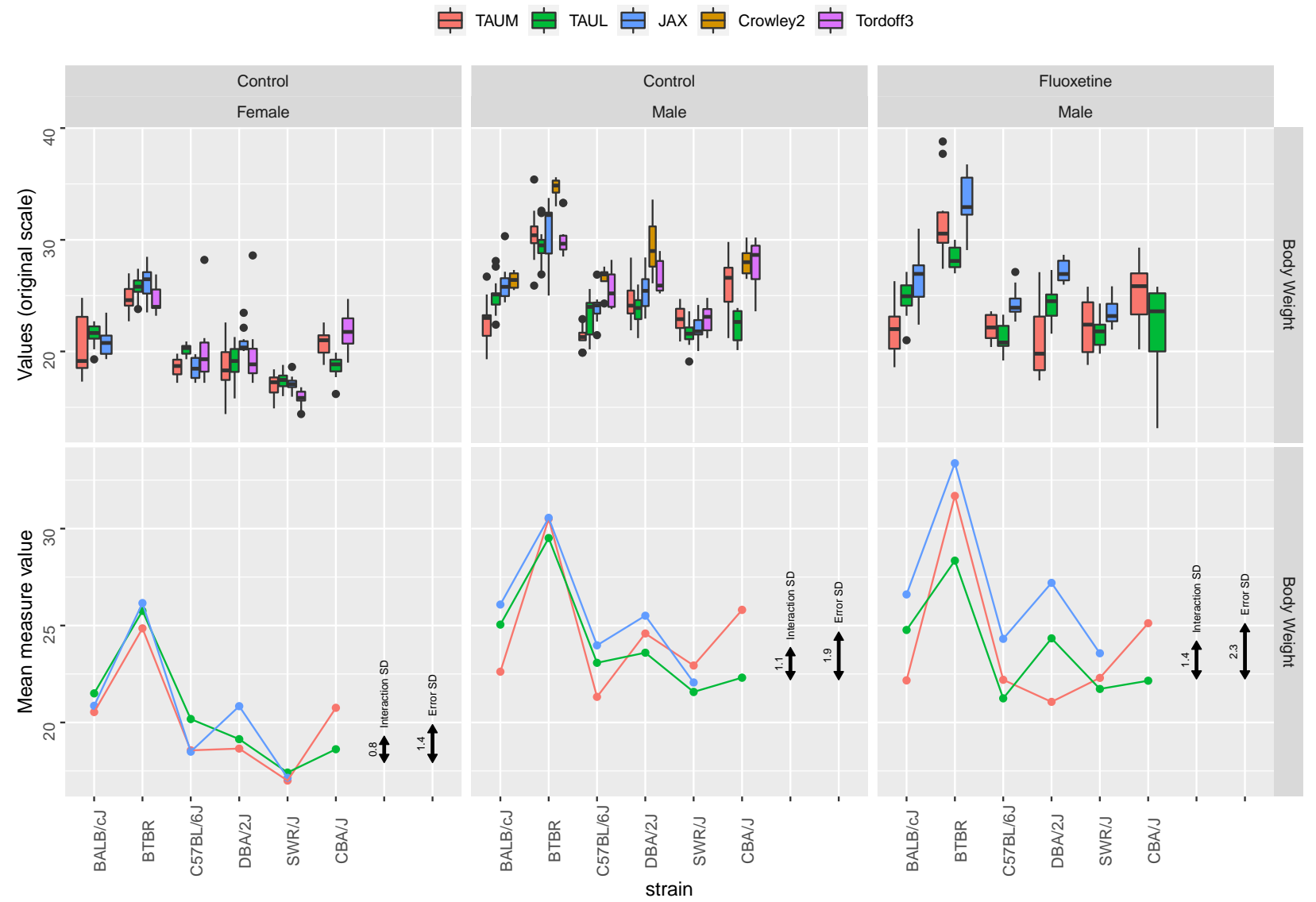

Figure 1. Body Weight (BW) in the 3 labs and in MPD studies Crowley1 and Tordoff3, using boxplots (top) and genotype means (bottom) in the three laboratories, in females (left), males (center) and fluoxetine-treated males (right). Black error bars represent the interaction SD and the within-group error SD.

As expected from a reliably-measured and well-defined physiological phenotype such as BW, the standard deviation of the error within the groups is small relative to the average weight, about $1.4 / 20=0.07$ for females (left panel). Similarly the interaction $0.8 / 20=0.04$ is also relatively small. Yet the GxL factor, the ratio of these two standard deviations, is not negligible: $\gamma=0.8 / 1.4=0.57$. In the fluoxetine-treated males (right panel), the GxL factor remains about the same $\gamma=0.61$, although both the interaction standard deviation and the standard deviation of the error within groups increased, in fact by more than $50 \%$ (as evident from the bars.) 
bioRxiv preprint doi: https://doi.org/10.1101/2021.12.05.471264; this version posted December 7, 2021. The copyright holder for this preprint (which was not certified by peer review) is the author/funder, who has granted bioRxiv a license to display the preprint in perpetuity. It is made available under aCC-BY-NC-ND 4.0 International license.

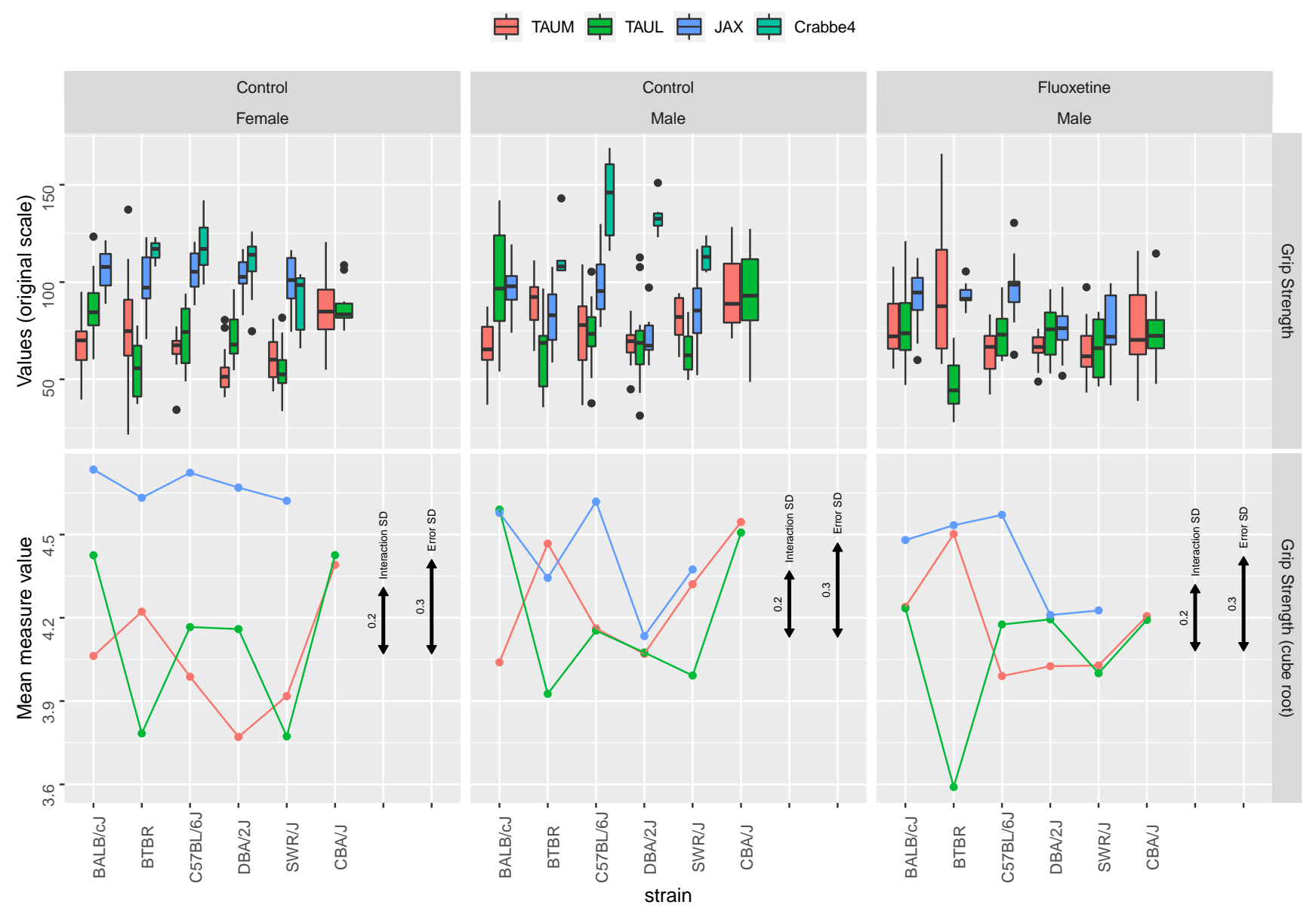

Figure 2: Grip Strength (GS) in the 3-lab and the MPD study Crabbe4. using boxplots (top) and genotype means after raising to the power of $1 / 3$ transformation (bottom) in the three laboratories: in females (left), males (center) and fluoxetinetreated males (right). Black error bars represent the interaction SD and the within-group error SD. 
bioRxiv preprint doi: https://doi.org/10.1101/2021.12.05.471264; this version posted December 7, 2021. The copyright holder for this preprint (which was not certified by peer review) is the author/funder, who has granted bioRxiv a license to display the preprint in perpetuity. It is made available under aCC-BY-NC-ND 4.0 International license.

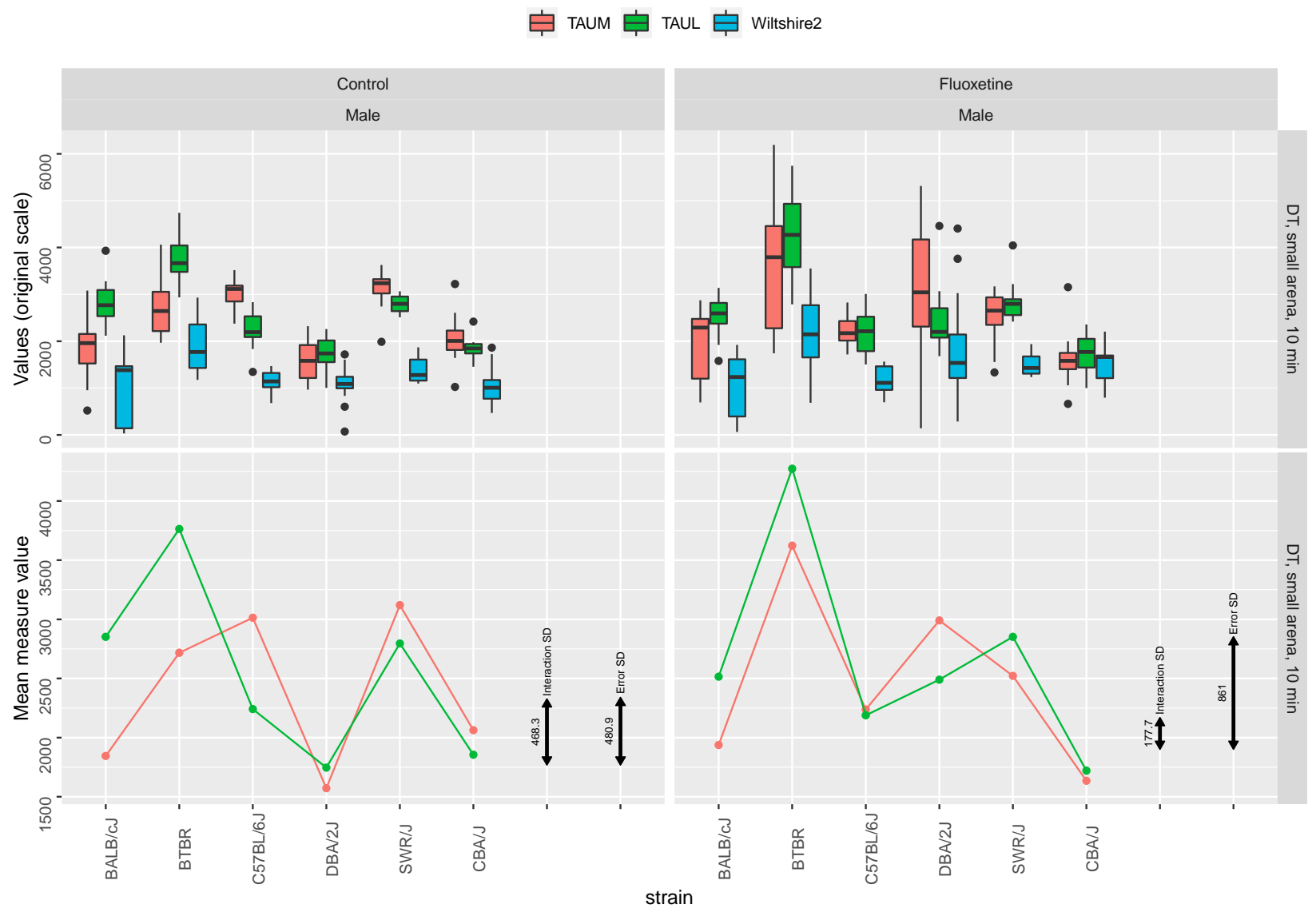

Figure 3: Distance Traveled (DT) in a small arena in 10 minutes, in the 3-lab and the MPD study Crabbe4. Grip Strength (GS) in the 3-lab and the MPD study Crabbe4. using boxplots (top) and genotype means (bottom) in the three laboratories: in females (left), males (center) and fluoxetine-treated males (right). Black error bars represent the interaction SD and the within-group error SD. 
bioRxiv preprint doi: https://doi.org/10.1101/2021.12.05.471264; this version posted December 7, 2021. The copyright holder for this preprint (which was not certified by peer review) is the author/funder, who has granted bioRxiv a license to display the preprint in perpetuity. It is made available under aCC-BY-NC-ND 4.0 International license.

官 TAUM 官 TAUL 追 JAX 官 Tarantino2
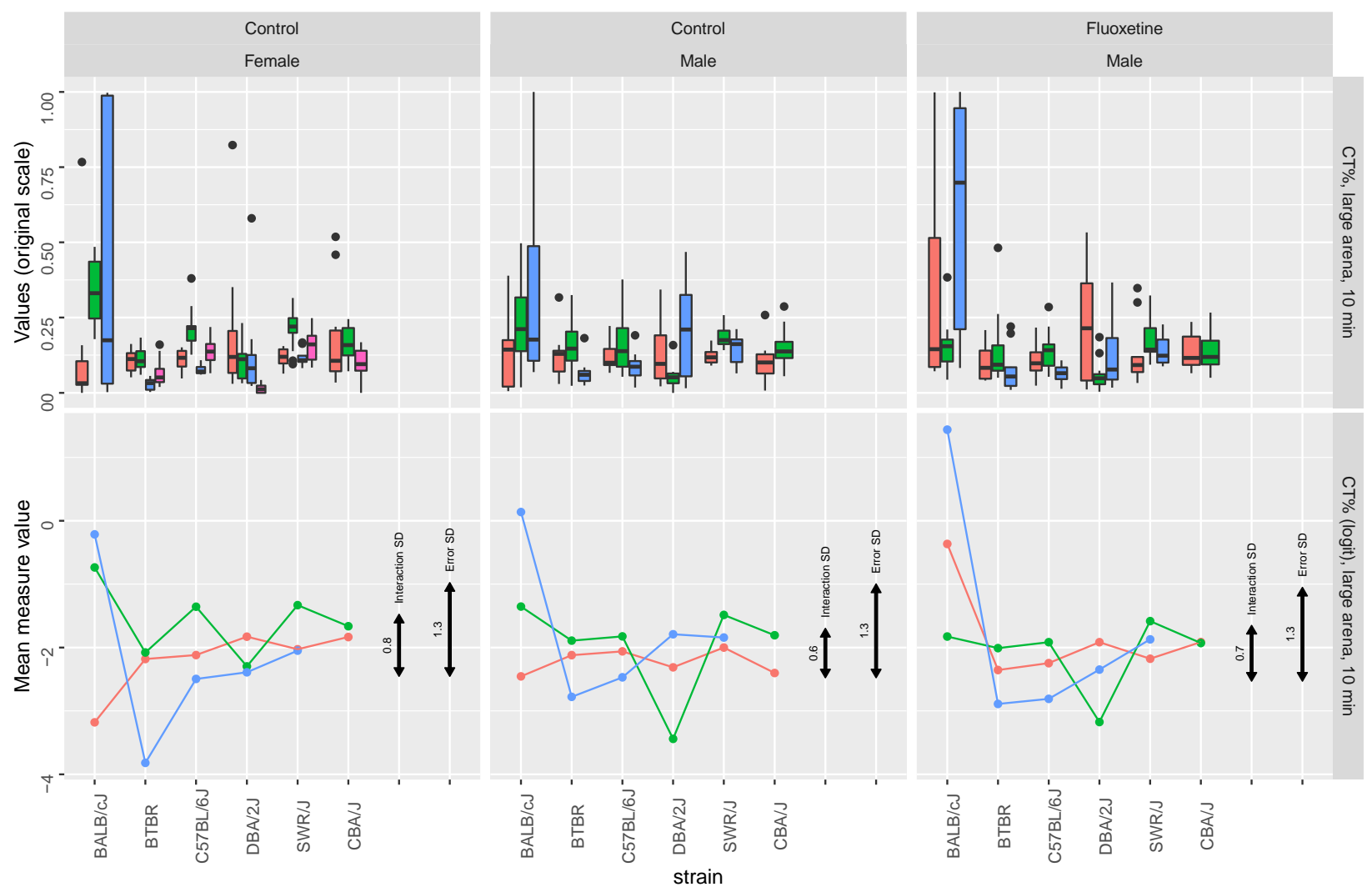

Figure 4: CT in the 3-lab, in a large arena for 10 minutes, and the MPD study Tarantino2 (for females). using boxplots (top) and genotype means after logit transformation (bottom) in the three laboratories: in females (left), males (center) and fluoxetine-treated males (right). Black error bars represent the interaction SD and the within-group error SD. 
bioRxiv preprint doi: https://doi.org/10.1101/2021.12.05.471264; this version posted December 7, 2021. The copyright holder for this preprint (which was not certified by peer review) is the author/funder, who has granted bioRxiv a license to display the preprint in perpetuity. It is made available under aCC-BY-NC-ND 4.0 International license.

\section{追 TAUM 追 TAUL 追 JAX 追 Wiltshire2}

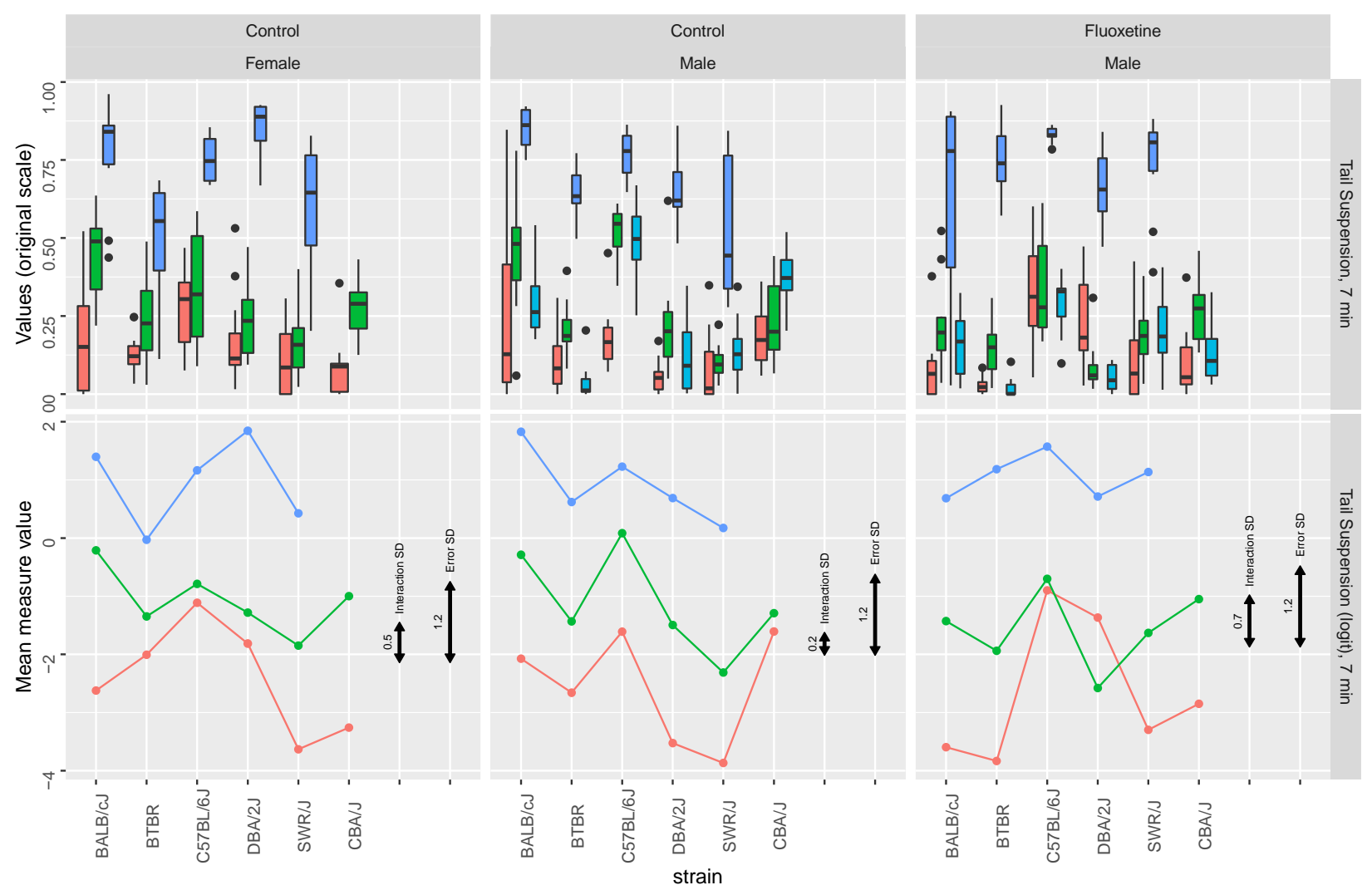

Figure 5: Tail Suspension (TS) test, \% time spent in immobility in 7 min, in the 3-lab experiment and the MPD study Wiltshire2. using boxplots (top) and genotype means after logit transformation (bottom) in the three laboratories: in females (left), males (center) and fluoxetine-treated males (right). Black error bars represent the interaction SD and the within-group error SD. 
bioRxiv preprint doi: https://doi.org/10.1101/2021.12.05.471264; this version posted December 7, 2021. The copyright holder for this preprint (which was not certified by peer review) is the author/funder, who has granted bioRxiv a license to display the preprint in perpetuity. It is made available under aCC-BY-NC-ND 4.0 International license.

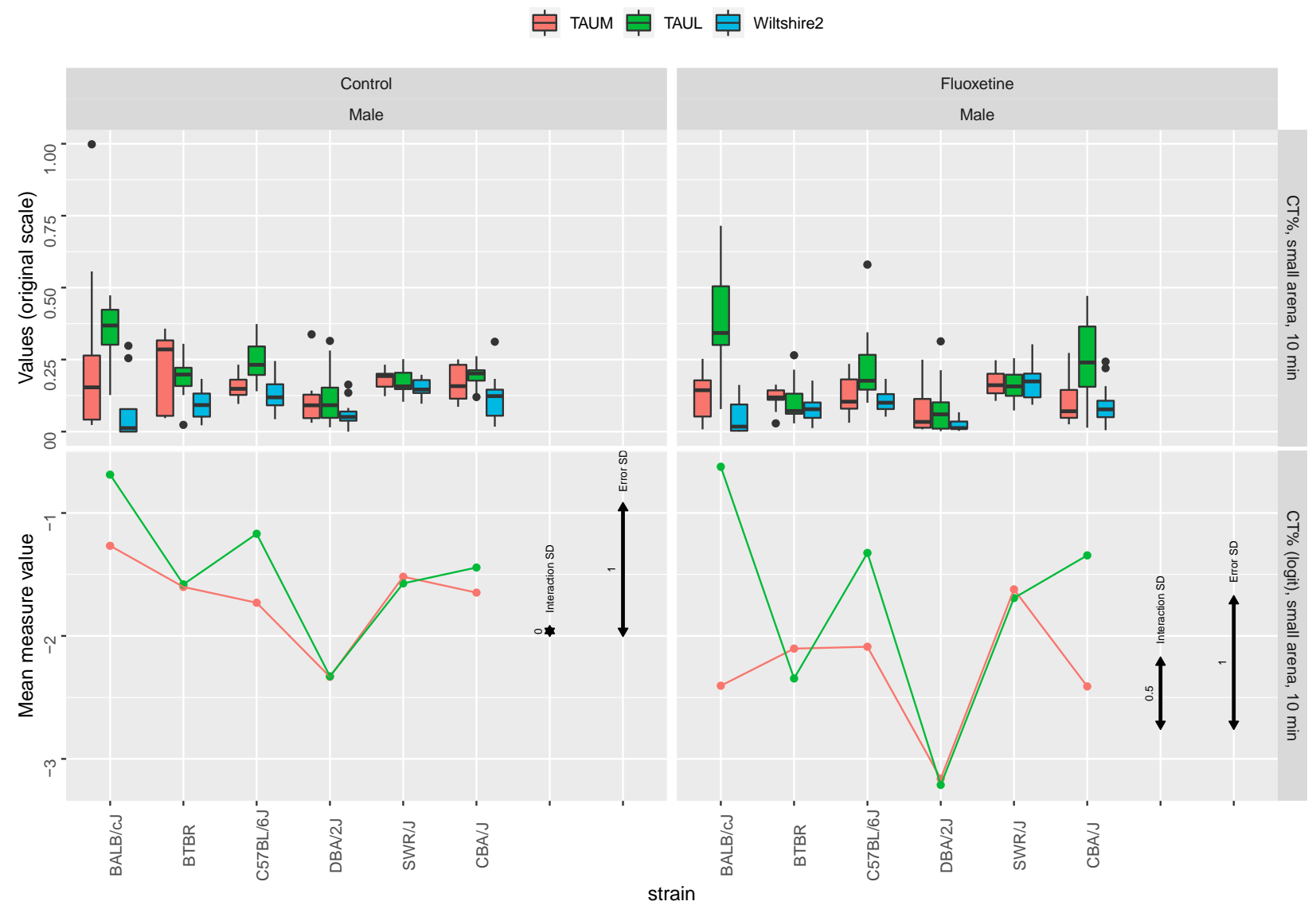

Figure 6: OF CT in the 3-lab and the MPD study Wiltshire2. using boxplots (top) and genotype means after logit transformation (bottom) in the three laboratories: in females (left), males (center) and fluoxetine-treated males (right). Black error bars represent the interaction SD and the within-group error SD. 


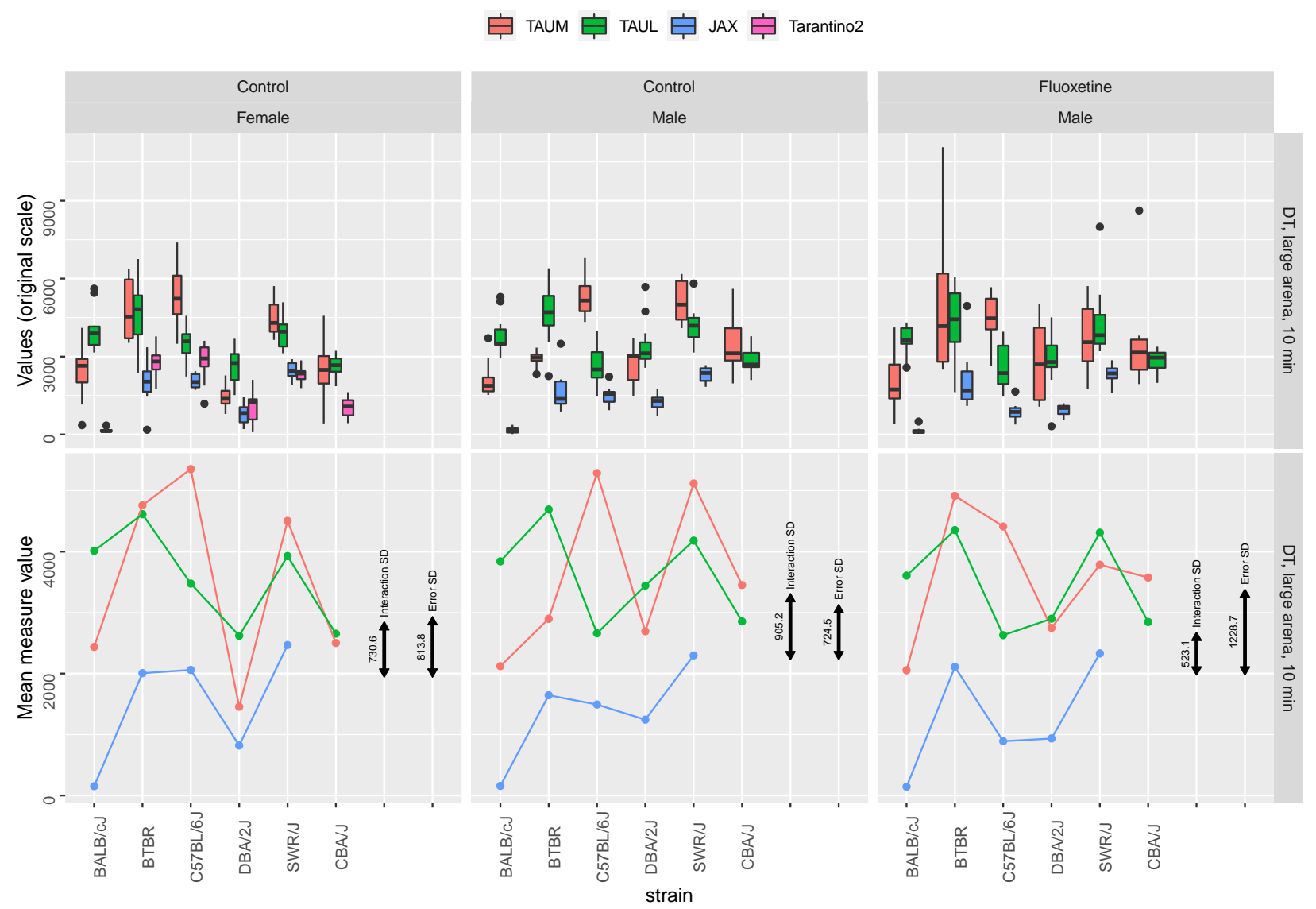

Figure 7: DT in the 3-lab, in a large arena for 10 minutes, and the MPD study Tarantino2 (for females). Graph organization is as in Figure 1, using boxplots (top) and genotype means (bottom) in the three laboratories: in females (left), males (center) and fluoxetine-treated males (right). Black error bars represent the interaction SD and the within-group error SD.

In some behavioral phenotypes, notably TS \% time spent in immobility (Fig. 5), there were large absolute lab differences. This is hardly surprising, however, considering our use of different measurement technologies (force transducer method in JAX, as opposed to video tracking in TAUM and TAUL), as well as the choice of analysis parameters, such as the cutoff value for detecting immobility, which was also left for the specific lab to determine, as in typical single-lab studies. Despite this, the standard deviation of the interaction is still considerably smaller than that of the error within.

For the DT endpoints, the estimated value of $\gamma$ was near or bigger than 1 (note especially Fig. 7 middle, where the interaction SD bar is actually longer than the Error SD bar). In contrast, all other phenotypes in this study had $\gamma$ considerably smaller than 1 (see Figure 8 for summary). This does not appear to be the fault of any single genotype, lab, sex or treatment. Indeed, large $\gamma$ occurred in all endpoints of DT, while they were still reasonable in the CT endpoints, which were measured in the same OF sessions (see discussion).

Note that in our experiment we could also measure related endpoints and variations in setups (such as 20 minutes OF instead of 10 ) that had no use for adjusting an MPD experiment. We still estimated $\gamma$ for 
bioRxiv preprint doi: https://doi.org/10.1101/2021.12.05.471264; this version posted December 7, 2021. The copyright holder for this preprint (which was not certified by peer review) is the author/funder, who has granted bioRxiv a license to display the preprint in perpetuity. It is made available under aCC-BY-NC-ND 4.0 International license.

them, teaching us about the robustness of the interaction. These are all presented in Figure 8 and Table S1.

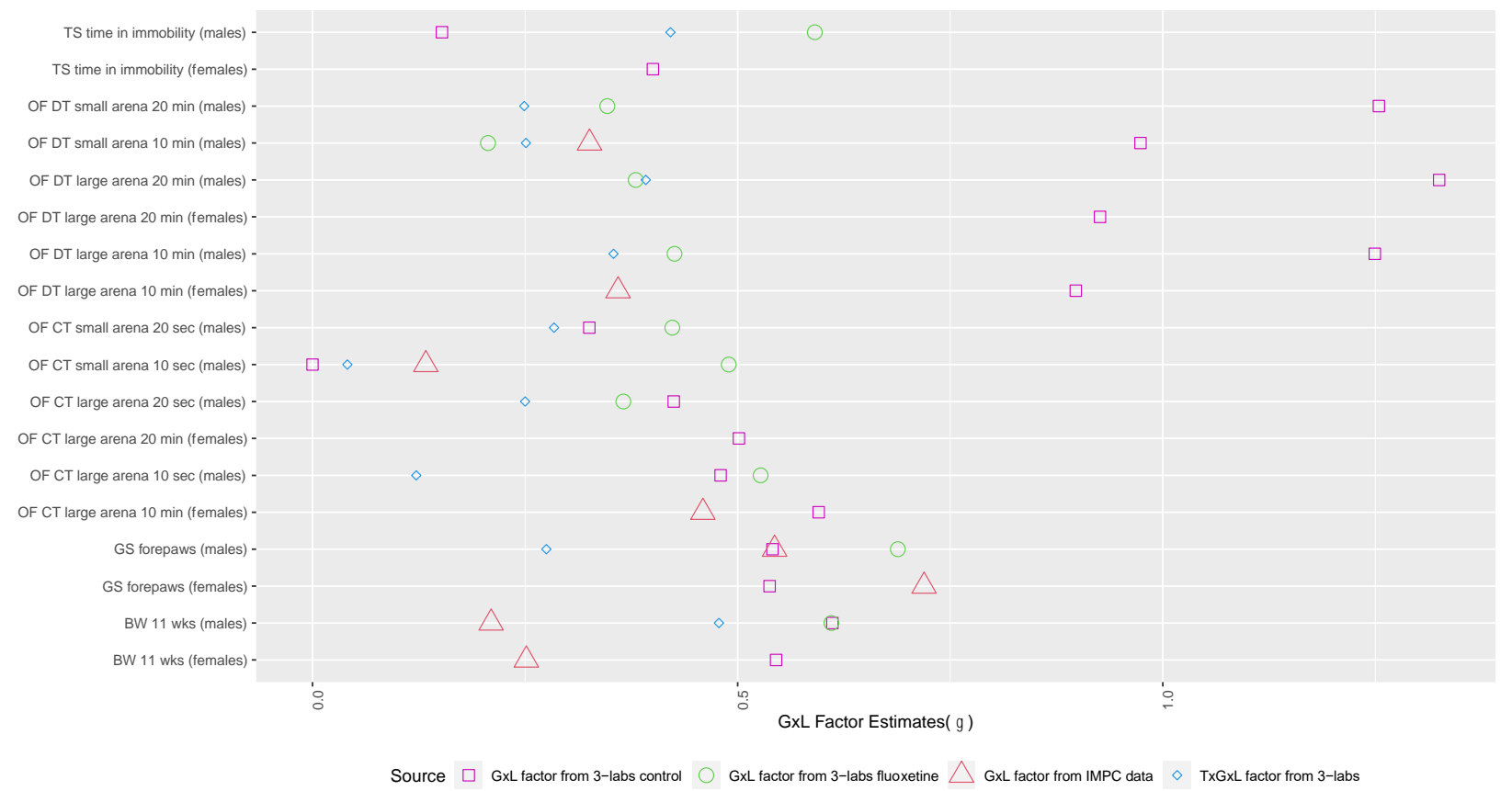

Figure 8: The values of the estimated interaction factor $\gamma$, for all endpoints as estimated from various sources: GxL factor from our 3-labs control data and from our fluoxetine treated data; GxL factor from IMPC data; TxGxL factor from our 3-labs data. CT and TS were logit transformed and GS was raised to the power of $1 / 3$.

\subsection{GxL-Adjustment of phenotyping results}

\subsubsection{GXL-adjustment of independent labs}

The effectiveness of GxL-adjustment in Kafkafi et al., (2017) was not demonstrated for a phenotyping laboratory that is independent of the laboratories being used to estimate the GxL-adjustment. In this subsection we use the dimensionless GxL factor $\gamma$, estimated from the 3-lab experiment described in Section 3.1, the values of which are presented in Table S1 and displayed in Fig. 8. We examine the implications of the adjustment over all phenotypic differences between any two genotypes available (see "Statistical Methods" and Table 3.) Table 4 presents the results.

Table 3: Results of naïve and GxL-adjusted genotypic differences for all phenotypes in the MPD experiments, using GxL factors estimated from the 3-lab.

\begin{tabular}{|l|l|l|l|}
\hline category & interpretation & $\begin{array}{l}\text { No. } \\
\text { cases }\end{array}$ & $\begin{array}{l}\% \\
\text { cases }\end{array}$ \\
\hline A & Replicable discoveries, approved by adjustment & 35 & \\
\hline B & Replicable discoveries, missed by adjustment & 11 & \\
\hline C & Replicable discoveries, missed by both & 7 & \\
\hline D & Non-replicable, insufficient adjustment & 12 & \\
\hline E & Non- replicable, prevented by adjustment & 47 & \\
\hline F & Non-replicable by both & 40 & \\
\hline
\end{tabular}




\begin{tabular}{|l|l|l|l|}
\hline$(D+E) /(D+E+F)$ & Proportion of non-replicable discoveries & $59 / 99$ & $59.6 \%$ \\
\hline$(D) /(D+E+F)$ & Proportion of non-replicable discoveries, GxL-adjusted & $12 / 99$ & $12.1 \%$ \\
\hline$(A+B) /(A+B+C)$ & Power to discover replicable discoveries & $46 / 53$ & $86.7 \%$ \\
\hline$(A) /(A+B+C)$ & Power to discover replicable discoveries, GxL-adjusted & $35 / 53$ & $66.0 \%$ \\
\hline
\end{tabular}

Out of the original studies' significant findings, 60\% (59/99) did not replicate in our 3-lab study. GxLadjustment considerably decreased this proportion of non-replicable discoveries to $12 \%(12 / 99)$. The price paid in decreased power to detect replicable discoveries was a decrease from $87 \%(46 / 53)$ to $66 \%(35 / 53)$. In absolute terms, 47 non-replicable "discoveries" were prevented, while only 11 replicable discoveries were missed.

\subsubsection{GxL-adjustment using IMPC data}

As in the previous section 3.2.1, in this section we use our 3-lab study for establishing the "ground truth", where a statistically significant difference according to the RLM is considered as a "replicable discovery". We also examine to what extent the number of non-replicable discoveries in an independent lab would have been reduced by adjusting it. However, unlike in 3.2.1 we use the GxL-interaction previously calculated from the IMPC multi-lab database (Kafkafi et al., 2017). The values of $\gamma$ for the different endpoints are presented in Table S1 and displayed in Figure 8. Since IMPC database does not contain data of fluoxetine-treated mice, and does not include a TS test, the number of available genotypic differences in phenotypes is reduced to 92 . Table 5 presents the results.

Table 4: Results of naïve and GxL-adjusted genotypic differences for all phenotypes in the MPD experiments, using GxL factors estimated from the IMPC standardized data.

\begin{tabular}{|l|l|l|l|}
\hline category & interpretation & $\begin{array}{l}\text { No. } \\
\text { cases }\end{array}$ & $\begin{array}{l}\% \\
\text { cases }\end{array}$ \\
\hline A & Replicable discoveries, approved by adjustment & 29 & \\
\hline B & Replicable discoveries, missed by adjustment & 1 & \\
\hline C & Replicable discoveries missed by both & 3 & \\
\hline$D$ & Non-replicable, insufficient adjustment & 14 & \\
\hline$E$ & Non- replicable, prevented by adjustment & 16 & \\
\hline$F$ & Non-replicable by both & 29 & \\
\hline$(D+E) /(D+E+F)$ & Proportion of non-replicable discoveries & $30 / 59$ & $50.8 \%$ \\
\hline$(D) /(D+E+F)$ & Proportion of non-replicable discoveries, GxL-adjusted & $14 / 59$ & $23.7 \%$ \\
\hline$(A+B) /(A+B+C)$ & Power to discover replicable discoveries & $30 / 33$ & $90.9 \%$ \\
\hline$(A) /(A+B+C)$ & Power to discover replicable discoveries, GxL-adjusted & $29 / 33$ & $87.8 \%$ \\
\hline
\end{tabular}

Using the IMPC-derived GXL-adjustment decreased the proportion of non-replicable discoveries in the original single-lab MPD studies from $51 \%$ to $24 \%$, for the price in decreasing the power to detect replicable discoveries from $91 \%$ with no adjustment to $87 \%$. In absolute terms, 16 non-replicable "discoveries" were prevented, while only 1 replicable discovery was missed.

Comparing the adjustment offered by $\gamma$, as estimated from the standardized IMPC data as above, to the adjustment offered by $\gamma$ estimated from our non-standardized 3-lab study, we notice that the latter tend to be larger (see Figure 8 ), as expected. In order to study the implication of this difference, we report the 
results of the analysis presented in 3.2.1 restricted to the set of differences reported here. The MPD based GxL-adjustment results in a proportion of non-replicable "discoveries" of $24 \%$, while it is $10 \%$ when the adjustment is based on the 3-lab data. The power in the IMPC-based adjustment is $88 \%$, in comparison to $61 \%$ using 3-lab-based adjustment (see supplementary table S2.)

\subsection{Using GxL-adjustment for comparing drug-effects across genotypes}

\subsubsection{Fluoxetine effect across six shared genotypes}

Our 3-lab experiment shared six genotypes and three phenotypes with the Wiltshire2 study in the MPD, which estimated the effect of fluoxetine treatment. This study offers 15 treatment effects in genotypes and 45 pairwise comparisons of treatment effects between genotypes, where the "ground truth" could be derived from our 3-lab data, using a three-way random lab analysis with genotype-by-lab-by-treatment interaction. This interaction term is also relevant for adjusting single-lab comparisons of fluoxetine treatment between genotypes, so it could be estimated from the 3-lab experiment (see Statistical Methods.)

Table 6: Results of naïve and GxLxT-adjusted genotypic differences for Wiltshire2 experiment, using GxLxT factors estimated from the 3-lab data. The rightmost two columns present results regarding differences in Fluoxetine effect between genotypes, and the two columns left of them represent results regarding fluoxetine effect in single genotypes

\begin{tabular}{|c|c|c|c|c|c|}
\hline \multirow[b]{2}{*}{ category } & \multirow[b]{2}{*}{ interpretation } & \multicolumn{2}{|c|}{$\begin{array}{l}\text { Fluoxetine effect } \\
\text { in genotypes }\end{array}$} & \multicolumn{2}{|c|}{$\begin{array}{l}\text { Differences in } \\
\text { Fluoxetine } \\
\text { effect between } \\
\text { genotypes }\end{array}$} \\
\hline & & $\begin{array}{l}\text { No. } \\
\text { cases }\end{array}$ & $\begin{array}{l}\% \\
\text { cases }\end{array}$ & $\begin{array}{l}\text { No. } \\
\text { cases }\end{array}$ & $\begin{array}{l}\% \\
\text { cases }\end{array}$ \\
\hline A & Replicable discoveries, approved by adjustment & 1 & & 0 & \\
\hline B & Replicable discoveries, missed by adjustment & 1 & & 1 & \\
\hline $\mathrm{C}$ & Replicable discoveries missed by both & 2 & & 8 & \\
\hline $\mathrm{D}$ & Non-replicable, insufficient adjustment & 1 & & 0 & \\
\hline $\mathrm{E}$ & Non- replicable, prevented by adjustment & 2 & & 1 & \\
\hline $\mathrm{F}$ & Non-replicable by both & 11 & & 35 & \\
\hline$(D+E) /(D+E+F)$ & Proportion of non-replicable discoveries & $3 / 14$ & $21.4 \%$ & $1 / 36$ & $2.8 \%$ \\
\hline (D) $/(D+E+F)$ & Proportion of non-replicable discoveries, GxL-adjusted & $1 / 14$ & $7.1 \%$ & $0 / 36$ & 0 \\
\hline$(A+B) /(A+B+C)$ & Power to discover replicable discoveries & $2 / 4$ & $50 \%$ & $1 / 9$ & $11.1 \%$ \\
\hline$(A) /(A+B+C)$ & Power to discover replicable discoveries, GxL-adjusted & $1 / 4$ & $25 \%$ & $0 / 9$ & 0 \\
\hline
\end{tabular}

The number of results available for fluoxetine effect in genotypes is small, so the results of their adjustment should be viewed with much caution; The number of results for pairwise comparisons of fluoxetine effects between genotypes is larger, but most of them do not result in significant difference in the original study. Combining the two sets of results, the proportion of non-replicable discoveries was reduced from $8 \%(4 / 50)$ to $2 \%(1 / 50)$ by the adjustment, and the power to detect replicable discoveries was reduced from $23 \%(3 / 13)$ to $8 \%(1 / 13)$.

\subsubsection{Fluoxetine effect across 30 genotypes}

The Wiltshire2 MPD study included 30 genotypes, between which 1305 pairwise comparisons of treatment effect can be conducted, with 45 of these included in our 3-lab experiment, and were already reported in Table 6. These 1305 comparisons can be used to assess the effect of the GxL-adjustment from 3-lab data for the three phenotypes. However, we do not have ground truth for these differences. 
For 276 comparisons, the regular t-based linear contrasts for fluoxetine treatment effects found significant difference in Wiltshire2 data. Two hundred four of them (73\%) would become non-significant once the GXL-adjustment is used. The adjustment thus weeds out a large proportion of apparently significant differences, but we cannot tell if it is justifiable or not.

\subsection{Lowering the significance threshold in the original analysis}

One potential response to our previous results is that by incorporating the GxL-adjustment we have merely lowered the level of the test being used, and one can instead use a single lower level across all comparisons. We have tested the recommendation in Benjamin et al (2018) to use the 0.005 level for statistical significance in the original studies. Table 7 shows the rejection rates when adapting the uniformly more conservative threshold.

Table 7 Results of naïve testing and lower significance level of 0.005 genotypic differences for all phenotypes in the MPD experiments.

\begin{tabular}{|l|l|l|l|}
\hline category & interpretation & $\begin{array}{l}\text { No. } \\
\text { cases }\end{array}$ & $\begin{array}{l}\% \\
\text { cases }\end{array}$ \\
\hline A & Replicable discoveries, approved by adjustment & 15 & \\
\hline B & Replicable discoveries, missed by adjustment & 31 & \\
\hline C & Replicable discoveries missed by both & 7 & \\
\hline E & Non-replicable, insufficient adjustment & 3 & \\
\hline E & Non- replicable, prevented by adjustment & 56 & \\
\hline$(D+E) /(D+E+F)$ & Proportion of non-replicable discoveries & 40 & \\
\hline$(D) /(D+E+F)$ & Proportion of non-replicable discoveries, GxL-adjusted & $59 / 99$ & $59.6 \%$ \\
\hline$(A+B) /(A+B+C)$ & Power to discover replicable discoveries & $3 / 99$ & $3.0 \%$ \\
\hline$(A) /(A+B+C)$ & Power to discover replicable discoveries, GxL-adjusted & $46 / 53$ & $86.8 \%$ \\
\hline
\end{tabular}

Using the lower $\alpha=0.005$ indeed offers a more conservative test, where the proportion of the nonreplicable discoveries is reduced to $3 \%$, compared to the $12 \%$ using GXL-adjustment. However, this comes with a very large price in power, which is reduced to $28 \%$, comparing to $66 \%$ using the GXLadjustment.

\section{Discussion}

\subsection{The contribution of GxL-adjustment to replicability}

What performances can be expected from GxL-adjustment in realistic situations of single-lab studies, which are typically not standardized with other labs? The most direct answer to this question is given in Section 3.2.1. Using database-derived interaction estimates for body weight (BW), distance traveled (DT) and center time (CT) in the open field test, grip strength, and tail suspension the GXL-adjustment reduced the number of false discoveries by half, from $60 \%$ to $12 \%$. This came with smaller loss of power, from $87 \%$ to $66 \%$. In absolute terms, 47 non-replicable "discoveries" were prevented, while only 11 replicable discoveries were missed. It is important to emphasize that the original studies used only few of the genotypes from which GxL-interactions were estimated. The testing parameters and conditions of testing were also not exactly the same in both. 
It might be argued that our success is merely due to our lowered thresholds for significance, and lowering the significance to .005, as suggested in Benjamin et al., (2018) and its many supporters, will have similar results. As shown in Section 3.4, when implementing this suggestion for the above set of MPD original results, the result was so conservative that the power was $27 \%$, instead of the above $60 \%$. The GxLadjustment takes into consideration the different levels of adjustment needed for the different endpoints when facing multi-lab replicability challenge, while using a single lower statistical discovery threshold across all phenotypes ignores the nature and robustness of each individual phenotype. Clearly there is an advantage to offering differing yardsticks to the different endpoints.

\subsection{GxL adjustment by standardized multi-lab data}

By turning to the use of the IMPC data as the source for the GxL factor, we manage to stage the most realistic setting. The three tasks of i) generating the GxL-adjustment; ii) establishing the multi-lab "ground truth"; and iii) estimating the performances of the adjustment in single-lab studies, are conducted each in an independent set of laboratories: by the IMPC multi-lab data, the 3-lab experiment and MPD data respectively. Unfortunately, using IMPC data for this purpose has an inherent limitation. The standardized way by which this multi-lab study is conducted, that might not reflect in full the variability between labs in the protocol used, its execution, and local conditions, all of which are reflected in the GxL term, when regular laboratories work. Thus, it is not clear whether the proportion of non-replicable discoveries rate of $24 \%$ we get using the IMPC based adjustment, which is higher than the $10 \%$ we get using the 3 -lab data for adjustment, reflects the more realistic setup or the less realistic source of data. Nevertheless, even if the actual implementation of our approach will bound the proportion of non-replicable results at somewhere between $24 \%$ and $10 \%$, it far more comforting a number than the $61 \%$ offered by doing nothing.

These results further indicate that extending the current effort in the MPD to utilize varied experimental results, created under no special standardization, for estimating the GxL-adjustment, should yield better results than merely relying on a single large initiative such as IMPC. Because the breadth of phenotyping in the IMPC was necessarily limited, while the breadth of archival experiments is potentially unlimited, the use of a database of research results as in the MPD is a promising approach for evaluating replicability across a wide range of experiments. Moreover, the utility of the approach grows as the data resource is expanded.

\subsection{GxL-adjustment of drug-treatment discoveries}

A practical limitation of our effort to experimentally verify the utility of the GxL-adjustment for drug treatment experiments was the small number of results that were available for testing our approach. Indeed, the changes were small: there were only four strain differences in which the original and the adjusted analysis differed. However, relying on the analysis in Section 3.2.2, which offered hundreds of potential differences, by including many more genotypes, using the adjustment weeds out a large number of original discoveries. Of course, we have no way to verify the ground truth for these genotype differences that were not tested in the 3-lab experiment, so performances in non-replicable discoveries prevented and power decrease cannot be estimated, but the impact should be large. Reassuringly, the GxL factor estimated for fluoxetine for many phenotypes was larger by merely $5 \%$ than the value for control mice, and the 3-way interaction was close to that value. These two results suggest that it may 
mostly be a property of the phenotype used. Future work should establish whether the interaction of Labby-Drug-by-Genotype does not depend critically on the drug administered

\subsection{Identifying and restructuring problematic phenotypes}

It follows from our work that for an endpoint to be useful, its design should take into consideration the size of its GXL factor $\gamma$. This factor compares the interaction variability to the animals' variability, a point of view that may be different from current thinking. Body weight has small variability among animals, i.e., high precision, but its interaction term measured here was high. At the same time, tail suspension is notoriously known to be of high variability, but surprisingly the interaction is small (see also Fig 5 central column), and thus the ratio turned out close to that of body weight.

More surprisingly, in the common OF test, CT had a consistently smaller factor than DT. Indeed, DT has had the largest number of comparisons changed from replicable to non-replicable due to the adjustment. Interestingly, DT as well as the CT proved highly replicable in a previous OF test by some of us, in 8 inbred strains, some of them used in the current study, across three laboratories, all different than the laboratories in the current study (Kafkafi et al., 2005). Both the interaction and the Error SD were considerably smaller relative to the measured size, with $\gamma \approx 0.7$ (see Figure 1 and error bars in Kafkafi et al., 2005). However, this previous study was conducted in circular, much larger arenas $(\approx 250 \mathrm{~cm}$ diameter vs $\approx 40 \mathrm{~cm}$ width in the current study), while using standardized video tracking systems, and employing standardized SEE analysis for robust path smoothing and segmentation. The DT, being a measure of change in location across time, is probably more sensitive than $\mathrm{CT}$, a measure of location, to lab-specific tracking noise that depends on the tracking technology and parameters used in each laboratory (Hen et al. 2004).

Lipkind et al. (2004) demonstrated the use of multi-lab results to explicitly improve the design of the DT and $\mathrm{CT}$ endpoints with robust methods to achieve better replicability across laboratories. Thus, while Wurbel et al. (2021) recently argued against using behavioral tests, our stand is that behavioral testing should not be dropped but rather improved, not by specifying to finer resolution how the test should be conducted, but by directed design of test hardware and software for higher replicability.

Finally, is there a minimal GxL factor that is appropriate? We note that even for a well-behaving physiological measure such as body weight, the GxL factor is 0.3 , and few are smaller than 0.2 . This might imply throwing into the variance term an additional 2 times $0.2^{2} \approx 0.04$ may serve as a minimal replicability enhancing measure when an estimate is unavailable. (The 0.02 for \%CT at small arena during 10 minutes is exceptionally low, but it was measured from only two labs, and its uncertainty in it is high). This is reminiscent of the recommendation of how to brew tea in a teapot: "one teaspoon for every cup and one for the pot". Unfortunately, larger adjustments that depend on the phenotype measured are usually needed. 


\section{Acknowledgements}

This work was supported by the US-Israel Binational Science Foundation-US National Science Foundation (BSF-NSF 2016746) (NIH-NSF DA045401) The authors are grateful to Dr. Lior Bikoveski at the Myers Neuro-Behavioral Core Facility for his continuous support with our mouse behavioral studies at the Faculty of Medicine, Tel Aviv University. We gratefully acknowledge the contributions of Zoe Bichler, Laura Anderson, Torrian Green, Meaghan Dyer, Veronica Knickerbocker, and the Center for Biometric Analysis Service for expert assistance with phenotyping conducted at The Jackson Laboratory. We also gratefully acknowledge the contributions of Computational Sciences at The Jackson Laboratory. 
bioRxiv preprint doi: https://doi.org/10.1101/2021.12.05.471264: this version posted December 7. 2021. The copvriaht holder for this preprint (which was not certified by peer review) is the author/funder, who has granted bioRxiv a license to display the preprint in perpetuity. It is made available under aCC-BY-NC-ND 4.0 International license.

\section{Supplementary Material}

Table S1: Estimated GxL factors $\gamma$ for different subgroups and endpoints including those estimated from 3-way analysis of drug treatment genotype and labs and those estimated from IMPC experiments.

\begin{tabular}{|c|c|c|c|c|c|c|c|}
\hline Test & & Phenotype & $\begin{array}{l}\text { Session } \\
\text { length }\end{array}$ & Arena size & $\begin{array}{c}\text { 3-lab } \\
\text { GxL } \\
\text { factor }(\gamma)\end{array}$ & $\begin{array}{l}\text { IMPC } \\
\text { GxL } \\
\text { factor }\end{array}$ & $\begin{array}{c}\text { 3-lab } \\
\text { GxL factor } \\
\text { for } \\
\text { Fluoxetine }\end{array}$ \\
\hline \multirow[t]{16}{*}{ Open Field } & \multirow[t]{8}{*}{ Female } & \multirow[t]{4}{*}{ Dist. Traveled } & \multirow[t]{2}{*}{$10 \mathrm{~min}$} & Small & & & \\
\hline & & & & Large & 0.898 & 0.360 & \\
\hline & & & \multirow[b]{2}{*}{$20 \mathrm{~min}$} & Small & & & \\
\hline & & & & Large & 0.926 & & \\
\hline & & \multirow[t]{4}{*}{$\%$ Cent. Time } & \multirow[t]{2}{*}{$10 \mathrm{~min}$} & Small & & & \\
\hline & & & & Large & 0.595 & 0.459 & \\
\hline & & & \multirow[b]{2}{*}{$20 \mathrm{~min}$} & Small & & & \\
\hline & & & & Large & 0.501 & & \\
\hline & \multirow[t]{8}{*}{ Male } & \multirow[t]{4}{*}{ Dist. Traveled } & \multirow[t]{2}{*}{$10 \mathrm{~min}$} & Small & 0.974 & 0.325 & 0.206 \\
\hline & & & & Large & 1.250 & & 0.425 \\
\hline & & & \multirow[b]{2}{*}{$20 \mathrm{~min}$} & Small & 1.254 & & 0.346 \\
\hline & & & & Large & 1.325 & & 0.380 \\
\hline & & \multirow[t]{4}{*}{ \% Cent. Time } & \multirow[t]{2}{*}{$10 \mathrm{~min}$} & Small & 0.00 & 0.133 & 0.490 \\
\hline & & & & Large & 0.480 & & 0.527 \\
\hline & & & \multirow[b]{2}{*}{$20 \mathrm{~min}$} & Small & 0.325 & & 0.423 \\
\hline & & & & Large & 0.425 & & 0.365 \\
\hline \multirow[t]{2}{*}{ Grip Strength } & Female & & & & 0.537 & 0.719 & \\
\hline & Male & & & & 0.541 & 0.543 & 0.688 \\
\hline \multirow[t]{2}{*}{ Body Weight } & Female & & & & 0.545 & 0.266 & \\
\hline & Male & & & & 0.611 & 0.21 & 0.610 \\
\hline \multirow[t]{2}{*}{ Tail Suspension } & Female & & & & 0.400 & & \\
\hline & Male & & & & 0.152 & & 0.591 \\
\hline
\end{tabular}


bioRxiv preprint doi: https://doi org/10.1101/2021.12.05.471264 this version posted December 7, 2021. The copyright holder for this preprint (which was not certified by peer review) is the author/funder, who has granted bioRxiv a license to display the preprint in perpetuity. It is made available under aCC-BY-NC-ND 4.0 International license.

Table S2: Results of naïve and GxL-adjusted genotypic differences for all phenotypes in the MPD experiments, using GxL factors estimated from the IMPC standardized data.

\begin{tabular}{|l|l|l|l|}
\hline category & interpretation & $\begin{array}{l}\text { No. } \\
\text { cases }\end{array}$ & $\begin{array}{l}\% \\
\text { cases }\end{array}$ \\
\hline A & Replicable discoveries, approved by adjustment & 20 & \\
\hline B & Replicable discoveries, missed by adjustment & 10 & \\
\hline C & Replicable discoveries missed by both & 3 & \\
\hline$D$ & Non-replicable, insufficient adjustment & 6 & \\
\hline$E$ & Non- replicable, prevented by adjustment & 24 & \\
\hline$F$ & Non-replicable by both & 29 & \\
\hline$(D+E) /(D+E+F)$ & Proportion of non-replicable discoveries & $30 / 59$ & $50.9 \%$ \\
\hline$(D) /(D+E+F)$ & Proportion of non-replicable discoveries, GxL-adjusted & $6 / 59$ & $10.2 \%$ \\
\hline$(A+B) /(A+B+C)$ & Power to discover replicable discoveries & $30 / 33$ & $90.9 \%$ \\
\hline$(A) /(A+B+C)$ & Power to discover replicable discoveries, GxL-adjusted & $20 / 33$ & $60.6 \%$ \\
\hline
\end{tabular}




\section{References}

1. Ayadi A, Birling MC, Bottomley J, Bussell J, Fuchs H, Fray M, et al. (2012). Mouse large-scale phenotyping initiatives: Overview of the European mouse disease clinic (EUMODIC) and of the Wellcome Trust Sanger Institute Mouse Genetics Project. Mammalian Genome, 23(9), 600-610. doi: 10.1007/s00335-012-9418-y

2. Bates D, Maechler M, Bolker B, Walker S (2015). Fitting Linear Mixed-Effects Models Using Ime4. Journal of Statistical Software, 67(1), 1-48. doi:10.18637/jss.v067.i01.

3. Benjamin DJ, et al (2018). Redefine statistical significance. Nature human behaviour, 2(1), 6-10. doi 10.1038/s41562-017-0189-z

4. Benton CS, Miller BH, Skwerer S, Suzuki O, Schultz LE, Cameron MD, Marron JS, Pletcher MT, Wiltshire T. (2012) Evaluating genetic markers and neurobiochemical analytes for fluoxetine response using a panel of mouse inbred strains. Psychopharmacology (Berl). 221(2):297-315. doi: 10.1007/s00213-011-2574-z

5. Bogue MA, Philip VM, Walton DO, Grubb SC, Dunn MH, Kolishovski G, Emerson J, Mukherjee G, Stearns T, He H, Sinha V, Kadakkuzha B, Kunde-Ramamoorthy G, Chesler EJ (2020). Mouse Phenome Database: a data repository and analysis suite for curated primary mouse phenotype data. Nucleic acids research, 48(D1), D716-D723. doi: 10.1093/nar/gkz1032

6. Crabbe JC, Wahlsten D, Dudek BC (1999). Genetics of mouse behavior: interactions with laboratory environment. Science, 284(5420), 1670-1672.

7. Crabbe JC, Cotnam CJ, Cameron AJ, Schlumbohm JP, Rhodes JS, Metten P, Wahlsten D (2003) Strain differences in three measures of ethanol intoxication in mice: the screen, dowel and grip strength tests. Genes Brain Behav. 2(4):201-13. doi: 10.1034/j.1601-183X.2003.00023.x

8. Crowley JJ, Adkins DE, Pratt AL, Quackenbush CR, van den Oord EJ, Moy SS, Wilhelmsen KC, Cooper TB, Bogue MA, McLeod HL, Sullivan PF. (2012) Antipsychotic-induced vacuous chewing movements and extrapyramidal side effects are highly heritable in mice. Pharmacogenomics $J$. 12(2):147-55. doi: 10.1038/tpj.2010.82.

9. de Angelis, M. H., Nicholson, G., Selloum, M., White, J. K., Morgan, H., Ramirez-Solis, R., et al. (2015). Analysis of mammalian gene function through broad-based phenotypic screens across a consortium of mouse clinics. Nature genetics, 47(9), 969-978. doi: 10.1038/ng.3360

10. Gozes I, Glowa J, Brenneman DE, McCune SK, Lee E, Westphal H (1993) Learning and sexual deficiencies in transgenic mice carrying a chimeric vasoactive intestinal peptide gene. $J \mathrm{Mol}$ Neurosci. 4(3):185-93. doi: 10.1007/BF02782501.

11. Hothorn T, Bretz F, Westfall P (2008). Simultaneous Inference in General Parametric Models. Biometrical Journal 50(3), 346--363.

12. Hacohen-Kleiman G, Sragovich S, Karmon, G, Gao AY, Grigg I, Pasmanik-Chor M, et al (2018). Activity-dependent neuroprotective protein deficiency models synaptic and developmental phenotypes of autism-like syndrome. The Journal of clinical investigation, 128(11), 4956-4969. doi: $10.1172 / \mathrm{JCl} 98199$ 
13. Hen I, Sakov A, Kafkafi N, Golani I, \& Benjamini Y (2004). The dynamics of spatial behavior: how can robust smoothing techniques help? Journal of neuroscience methods, 133(1-2), 161-172.

14. Javitt DC, Buchanan RW, Keefe RS, Kern R, McMahon RP, Green MF, et al. (2012). Effect of the neuroprotective peptide davunetide (AL-108) on cognition and functional capacity in schizophrenia. Schizophrenia research, 136(1-3), 25-31. doi: 10.1016/j.schres.2011.11.001

15. Kafkafi, N., Benjamini, Y., Sakov, A., Elmer, G. I., \& Golani, I. (2005). Genotype-environment interactions in mouse behavior: a way out of the problem. Proceedings of the National Academy of Sciences, 102(12), 4619-4624. doi: 10.1073pnas.040955410

16. Kafkafi N, Golani I, Jaljuli I, Morgan H, Sarig T, Würbel H, Yaacoby S, Benjamini Y (2017). Addressing reproducibility in single-laboratory phenotyping experiments. Nature methods, 14(5), 462-464. doi: 10.1007/BF02782501

17. Kafkafi N, Agassi J, Chesler EJ, Crabbe JC, Crusio WE, Eilam D, et al (2018). Reproducibility and replicability of rodent phenotyping in preclinical studies. Neuroscience \& Biobehavioral Reviews, 87, 218-232. 10.1016/j.neubiorev.2018.01.003

18. Karmon G, Sragovich S, Hacohen-Kleiman G, Ben-Horin-Hazak I, Kasparek P, Schuster B, et al (2021). Novel ADNP syndrome mice reveal dramatic sex-specific peripheral gene expression with brain synaptic and Tau pathologies. Biological Psychiatry.

19. Lipkind D, Sakov A, Kafkafi N, Elmer GI, Benjamini Y, Golani I (2004). New replicable anxietyrelated measures of wall vs. center behavior of mice in the open field. Journal of applied physiology, 97(1), 347-359. doi: org/10.1152/japplphysiol.00148.2004

20. Muñoz-Fuentes V, Cacheiro P, Meehan TF, Aguilar-Pimentel JA, Brown SD, Flenniken AM et al. (2018). The International Mouse Phenotyping Consortium (IMPC): a functional catalogue of the mammalian genome that informs conservation. Conservation Genetics, 19(4), 995-1005. doi: $10.1038 / \mathrm{s} 41576-018-0005-2$

21. Pinheiro J, Bates D, DebRoy S, Sarkar D, R Core Team (2021). nlme: Linear and Nonlinear Mixed Effects Models. R package version 3.1-152, https://CRAN.R-project.org/package=nlme.

22. Quraishe S, Cowan CM, Mudher A. (2013) NAP (davunetide) rescues neuronal dysfunction in a Drosophila model of tauopathy. Mol Psychiatry. 18(7):834-42. doi: 10.1038/mp.2013.32.

23. R Core Team (2021). R: A language and environment for statistical computing. R Foundation for Statistical Computing, Vienna, Austria. https://www.R-project.org/.

24. Schoenrock SA, Oreper D, Young N, Ervin RB, Bogue MA, Valdar W, Tarantino LM. (2016) Ovariectomy results in inbred strain-specific increases in anxiety-like behavior in mice. Physiol Behav. 167:404-412. doi: 10.1016/j.physbeh.2016.09.026.

25. Tordoff MG, Bachmanov AA, Reed DR. (2007) Forty mouse strain survey of water and sodium intake. Physiol Behav. 91(5):620-31. doi: 10.1016/j.physbeh.2007.03.025

26. Wickham H, "ggplot2: Elegant Graphics for Data Analysis". Springer-Verlag New York, 2016. 
27. VoelkI B, Vogt L, Sena ES, Würbel H (2018). Reproducibility of preclinical animal research improves with heterogeneity of study samples. PLoS biology, 16(2), e2003693. doi:

10.1371/journal.pbio.2003693

28. Vulih-Shultzman I, Pinhasov A, Mandel S, Grigoriadis N, Touloumi O, Pittel Z, Gozes I. (2007) Activity-dependent neuroprotective protein snippet NAP reduces tau hyperphosphorylation and enhances learning in a novel transgenic mouse model. J Pharmacol Exp Ther 323(2):438-49. doi: 10.1124/jpet.107.129551.

29. Rosso M, Wirz R Loretan AV et al (2021) Reliability of Mouse Behavioural Tests of Anxiety: a Systematic Review and Meta-Analysis on the Effects of Anxiolytics. Preprint DOI: 